\title{
Functional inhibition of acid sphingomyelinase disrupts infection by intracellular bacterial pathogens
}

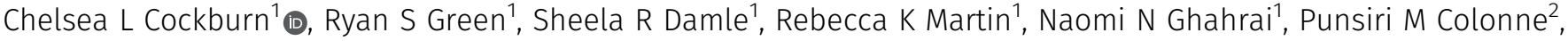 \\ Marissa S Fullerton², Daniel H Conrad ${ }^{1}$, Charles E Chalfant ${ }^{3}$, Daniel E Voth², Elizabeth A Rucks ${ }^{4} \mathbb{D}$, Stacey D Gilk ${ }^{5}$, \\ Jason A Carlyon ${ }^{1}$ (1)
}

Intracellular bacteria that live in host cell-derived vacuoles are significant causes of human disease. Parasitism of low-density lipoprotein (LDL) cholesterol is essential for many vacuoleadapted bacteria. Acid sphingomyelinase (ASM) influences LDL cholesterol egress from the lysosome. Using functional inhibitors of ASM (FIASMAs), we show that ASM activity is key for infection cycles of vacuole-adapted bacteria that target cholesterol trafficking-Anaplasma phagocytophilum, Coxiella burnetii, Chlamydia trachomatis, and Chlamydia pneumoniae. Vacuole maturation, replication, and infectious progeny generation by $A$. phagocytophilum, which exclusively hijacks LDL cholesterol, are halted and $C$. burnetii, for which lysosomal cholesterol accumulation is bactericidal, is killed by FIASMAs. Infection cycles of Chlamydiae, which hijack LDL cholesterol and other lipid sources, are suppressed but less so than A. phagocytophilum or C. burnetii. A. phagocytophilum fails to productively infect $\mathrm{ASM}^{-1-}$ or FIASMAtreated mice. These findings establish the importance of ASM for infection by intracellular bacteria and identify FIASMAs as potential host-directed therapies for diseases caused by pathogens that manipulate LDL cholesterol.

DOI 10.26508/Isa.201800292 | Received 30 December 2018 | Revised 12 March 2019 | Accepted 13 March 2019 | Published online 22 March 2019

\section{Introduction}

Intracellular bacteria that reside exclusively within host cellderived vacuoles are major causes of disease in terms of both incidence and severity. If left untreated, the resulting infections can be severe, even fatal, or can become chronic and lead to extended periods of debilitation. Although certain antibiotics can effectively treat many of these diseases, bacterial resistance has been reported and allergy can occur (Jones et al, 1990; Lefevre et al, 1997; Somani et al, 2000; Spyridaki et al, 2002; Sandoz \& Rockey, 2010;
Rouli et al, 2012), signifying the need for effective alternative therapeutics.

Parasitism of lipids, particularly cholesterol, is essential for intracellular bacterial pathogen infectivity [reviewed in Samanta et al (2017); Walpole et al (2018)]. Cholesterol is a major lipid component of eukaryotic membranes that influences membrane rigidity and is involved in diverse cellular processes including signal transduction, gene transcription, protein function and degradation, endocytic and Golgi trafficking, and intra-organelle membrane contact site formation. In mammalian cells, whereas cholesterol can be synthesized de novo in the endoplasmic reticulum, most is acquired exogenously via the low-density lipoprotein (LDL) receptor. After LDL uptake, esterified cholesterol is trafficked by the endocytic route to lysosomes, where it is hydrolyzed to unesterified free cholesterol molecules that are delivered to the plasma membrane, trans-Golgi network (TGN), endoplasmic reticulum, and ultimately throughout the cell (Urano et al, 2008; Samanta et al, 2017; Walpole et al, 2018). Lysosomes therefore play an essential role in intracellular cholesterol homeostasis (Kuzu et al, 2017).

Inhibition of lysosomal cholesterol efflux occurs in lipid storage disorders, such as Niemann-Pick disease (Brady et al, 1966). The type $A$ and $B$ forms of this condition result from loss of function mutations in acid sphingomyelinase (ASM), a lysosomal enzyme that hydrolyzes sphingomyelin to yield phosphorylcholine and ceramide (Vanier, 2013). ASM deficiency leads to sphingomyelin accumulation in lysosomes, which, in turn, blocks LDL-derived cholesterol efflux (Lloyd-Evans et al, 2008). Niemann-Pick disease severity correlates with decreased ASM activity (Schuchman \& Miranda, 1997). Conversely, ASM activation has also been linked to the development of multiple human diseases [reviewed in Schuchman (2010); Kornhuber et al (2015)], and studies using cells from Niemann-Pick patients or ASM knockout mice indicate that ASM deficiency might also have beneficial consequences [reviewed in Kornhuber et al (2010)]. Indeed, functional inhibitors of ASM (FIASMAs) have emerged as promising drugs with broad therapeutic

${ }^{1}$ Department of Microbiology and Immunology, Virginia Commonwealth University Medical Center, School of Medicine, Richmond, VA, USA ${ }^{2}$ Department of Microbiology and Immunology, University of Arkansas for Medical Sciences, Little Rock, AR, USA ${ }^{3}$ Department of Cell Biology, Microbiology, and Molecular Biology, University of South Florida, Tampa, FL, USA ${ }^{4}$ Department of Pathology and Microbiology, University of Nebraska Medical Center, Omaha, NE, USA ${ }^{5}$ Department of Microbiology and Immunology, Indiana University School of Medicine, Indianapolis, IN, USA

Correspondence: jason.carlyon@vcuhealth.org 
potential (Kornhuber et al, 2010; Kuzu et al, 2017). FIASMAs are lysosomotropic compounds that indirectly inactivate ASM by promoting its detachment from the inner lysosomal membrane, rendering it susceptible to proteolysis. FIASMAs are active in cell culture models and in vivo at concentrations that are therapeutically achieved during pharmacotherapy in humans. Many FIASMAs are FDA approved for clinical use in humans (Kornhuber et al, 2010).

Some studies have investigated ASM's relevance to microbial infections and FIASMAs' potential therapeutic benefit in this context. For instance, FIASMA treatment protects mice from superoxidemediated lung edema associated with Staphylococcus aureus infection and prevents lethal S. aureus sepsis when administered together with antibiotics (Peng et al, 2015). Also, paradoxically, whereas ASM-mediated phagosome maturation is important for controlling mycobacterial infection, ASM-dependent cell-cell fusion can provide an innate immunoescape niche for mycobacterial replication (Utermohlen et al, 2008; Vazquez et al, 2016; Wu et al, 2018). Given that multiple intracellular bacterial pathogens hijack LDL cholesterol trafficking and storage pathways for growth and/or survival [reviewed in Samanta et al (2017); Walpole et al (2018)], FIASMAs could represent novel, non-antibiotic means for treating the diseases that these bacteria cause. Yet, their potential in this capacity and the importance of ASM in intracellular bacterial infections that involve cholesterol parasitism have gone largely unexplored.

Here, we demonstrate that ASM activity is essential for optimal infection cycle progression of four obligate intracellular vacuoleadapted bacterial pathogens that target host cholesterol trafficking pathways: Anaplasma phagocytophilum (Xiong et al, 2009; Xiong \& Rikihisa, 2012), Coxiella burnetii (Howe \& Heinzen, 2006; Mulye et al, 2018), Chlamydia trachomatis (Carabeo et al, 2003; Beatty, 2006, 2008; Kumar et al, 2006; Cocchiaro et al, 2008; Cox et al, 2012), and Chlamydia pneumoniae (Liu et al, 2010). The degree of FIASMA-mediated inhibition correlates with pathogen dependency on LDL cholesterol. ASM-deficient mice are resistant to A. phagocytophilum infection and FIASMA administration postinfection prevents the bacterium from productively infecting wild-type (WT) mice. Overall, this study establishes the importance of ASM to infection by multiple intracellular bacteria and distinguishes FIASMAs as potential therapeutics for diseases caused by pathogens whose growth is influenced by LDL cholesterol.

\section{Results}

\section{Functional inhibition of host cell ASM reduces the A. phagocytophilum load}

A. phagocytophilum infects neutrophils to cause the emerging disease human granulocytic anaplasmosis, which presents as an acute nonspecific febrile illness that can progress to severe complications or death in immunocompromised patients, the elderly, and in the absence of antibiotic intervention (Ismail \& McBride, 2017). A. phagocytophilum lacks genes required for lipid A biosynthesis and most peptidoglycan synthesis genes (Lin \& Rikihisa, 2003; Dunning Hotopp et al, 2006). The bacterium incorporates cholesterol into its fragile cell envelope and requires the lipid for intracellular replication, but is devoid of genes encoding cholesterol biosynthesis or modification enzymes and must parasitize the sterol from host cells (Lin \& Rikihisa, 2003). A. phagocytophilum obtains cholesterol exclusively by hijacking the Niemann-Pick type C protein 1 (NPC1) pathway that mediates lysosomal cholesterol efflux (Xiong et al, 2009; Xiong \& Rikihisa, 2012), which makes it an ideal organism for evaluating the efficacy of FIASMAs for inhibiting infection by an LDL cholesterol-dependent pathogen.

Promyelocytic HL-60 and RF/6A endothelial cells are established models for examining A. phagocytophilum-host cell interactions (Klein et al, 1997; Munderloh et al, 2004; Truchan et al, 2016c). Desipramine is an FDA-approved tricyclic antidepressant that functionally inhibits ASM (Kornhuber et al, 2010). To determine if pharmacologic inhibition of ASM inhibits A. phagocytophilum infection, desipramine-treated HL-60 and RF/6A cells were incubated with A. phagocytophilum. PCR analyses at 24, 48 , and $72 \mathrm{~h}$ revealed that, although bacterial DNA levels increased throughout the time course in control cells, they were pronouncedly reduced and did not increase in desipramine-treated cells in a dose-dependent manner (Fig 1A-C). Desipramine also halted A. phagocytophilum infection in human neutrophils (Fig 1D). This experiment was only carried out for $32 \mathrm{~h}$ to allow completion of one bacterial infection cycle because, although $A$. phagocytophilum extends the 12-h half-life of neutrophils (Alberdi et al, 2016), cell death was observed after 32 h. Desipramine prevented an increase in A. phagocytophilum load when administered to $\mathrm{HL}-60$ cells at $24 \mathrm{~h}$ postinfection, thereby indicating its ability to inhibit active infection (Fig 1E). However, desipramine treatment had no effect on bacterial binding to host cells (Fig 1F). Although many bacterial sphingomyelinases function as virulence factors (Flores-Diaz et al, 2016), none are encoded by the annotated $A$. phagocytophilum genome (Dunning Hotopp et al, 2006). Nonetheless, to verify that the inhibitory effect of desipramine on A. phagocytophilum infection in host cells was not due to the drug directly acting on the bacterium, host cell-free A. phagocytophilum organisms were exposed to the drug or vehicle before incubation with HL-60 cells. The bacterial DNA load at $24 \mathrm{~h}$ postinfection was equivalent between host cells that had been pretreated with desipramine or that had not been treated (Fig 1G).

In addition to functionally inhibiting ASM, desipramine promotes degradation of acid ceramidase, which acts downstream of ASM to hydrolyze ceramide to sphingosine (Elojeimy et al, 2006; Kornhuber et al, 2010). Therefore, to confirm that desipramine's deleterious effect on A. phagocytophilum was specific to its action on ASM, HL60 cells were pretreated with CA-074 Me, which blocks desipramine's effect on acid ceramidase (Elojeimy et al, 2006), before successive incubations with desipramine and $A$. phagocytophilum. CA-074 Me failed to abrogate the desipramine-mediated arrest of $A$. phagocytophilum infection (Fig 1H). Amitriptyline and nortriptyline, two other FDA-approved tricyclic antidepressants and confirmed FIASMAs (Kornhuber et al, 2010), also suppress A. phagocytophilum infection (Fig 1 I and J). Collectively, these data indicate that pharmacologic inhibition of host cell-ASM activity prevents an increase in A. phagocytophilum load at a post-bacterial adhesion step and in a dose-dependent manner. 
A HL-60 cells

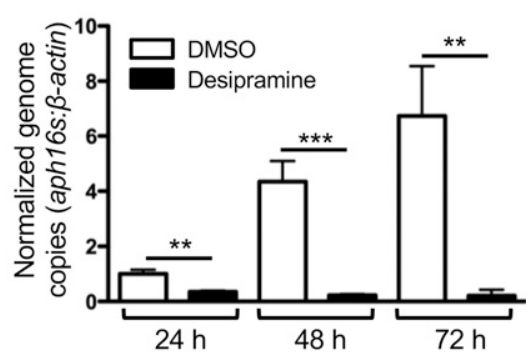

D Human neutrophils

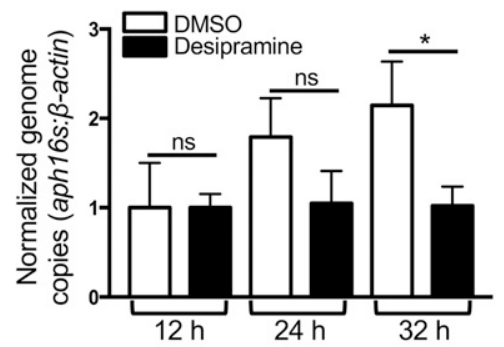

G HL-60 cells

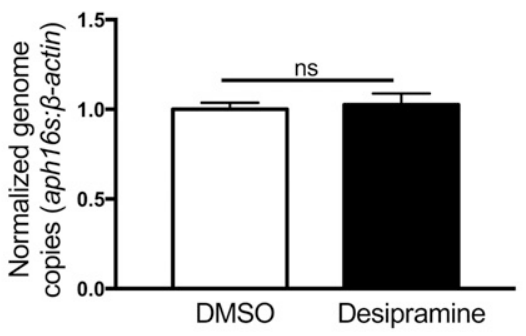

J HL-60 cells

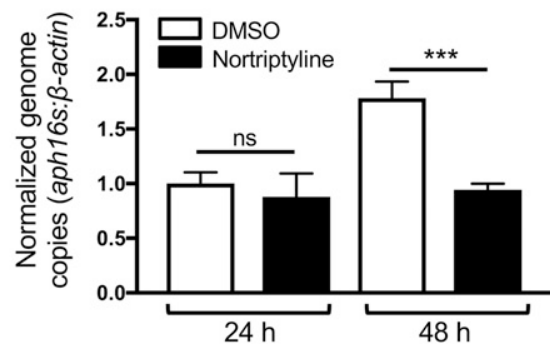

B HL-60 cells

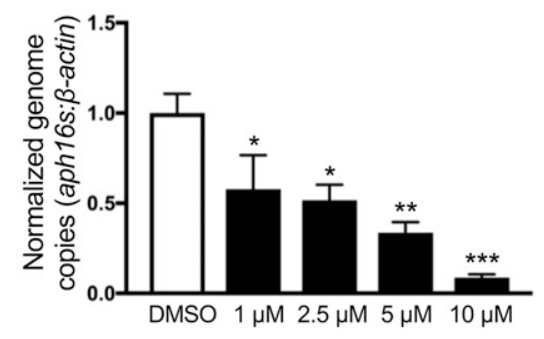

E HL-60 cells

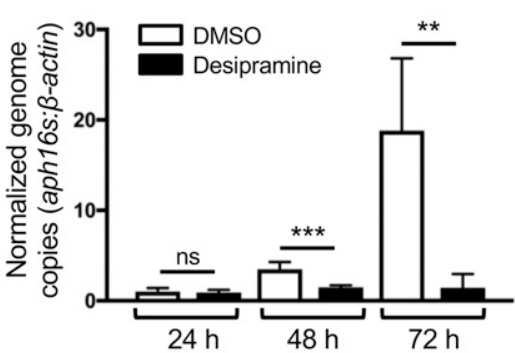

H HL-60 cells

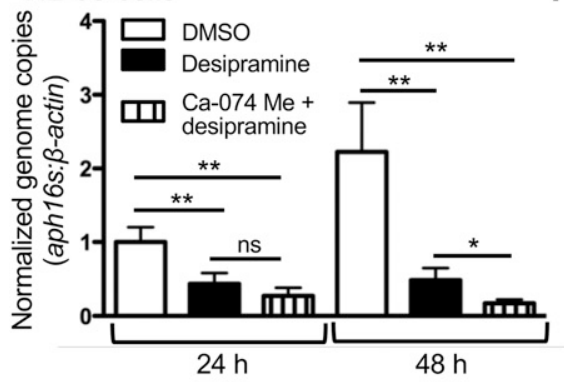

C RF/6A cells

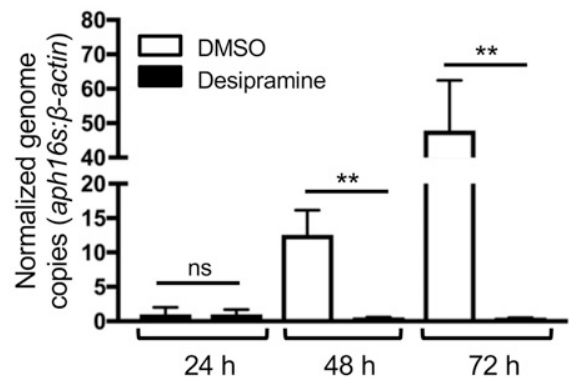

F RF/6A cells

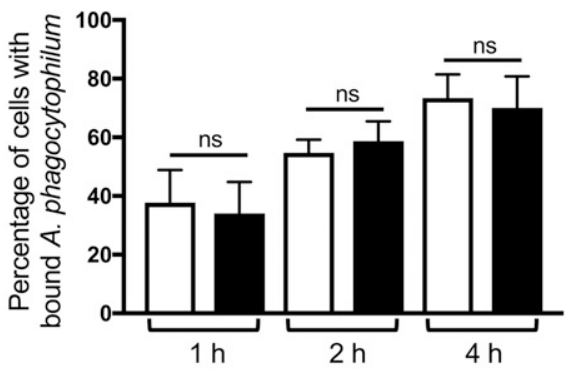

I HL-60 cells

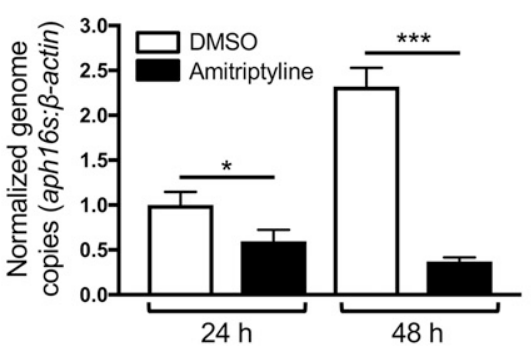

Figure 1. FIASMAs inhibit A. phagocytophilum infection at a post bacterial invasion step through specific targeting of host cell ASM.

(A-E, I, J) FIASMA treatment reduces the A. phagocytophilum DNA load in host cells. HL-60 cells (A, B, I, J), RF/6A cells (C), or human peripheral blood neutrophils (D) were treated with $10 \mu \mathrm{M}$ (unless otherwise noted) desipramine (A, B), amitriptyline (I), nortriptyline (J), or DMSO vehicle control followed by incubation with A. phagocytophilum organisms. Total DNA isolated at the indicated time points was analyzed by qPCR. Relative levels of the A. phagocytophilum 16S rRNA (aph16s) gene were normalized to the relative levels of $\beta$-actin using the $2^{-\triangle \Delta C T}$ method. (E) Desipramine was added to A. phagocytophilum-infected cells beginning at $24 \mathrm{~h}$ followed by qPCR analysis. (F) Desipramine has no effect on A. phagocytophilum binding to host cells. RF/6A cells were exposed to desipramine or DMSO followed by incubation with A. phagocytophilum. At 1, 2, and 4 h, the cells were fixed, immunolabeled with antibody against the A. phagocytophilum surface protein, P44, and examined by immunofluorescence microscopy to determine the percentages of cells having bound A. phagocytophilum organisms. (G) Desipramine treatment of A. phagocytophilum does not alter infection of host cells. Host cell-free A. phagocytophilum bacteria were exposed to desipramine or DMSO followed by incubation with untreated HL-60 cells At $24 \mathrm{~h}$, the bacterial load was determined using qPCR. (H) The inhibitory effect of desipramine on A. phagocytophilum infection is due to its action on ASM, not acid ceramidase. HL-60 cells were treated with CA-074 Me or not followed by treatment with desipramine or vehicle control. The cells were then infected with $\mathrm{A}$. phagocytophilum. At 24 and $48 \mathrm{~h}$, the bacterial load was measured using qPCR. Error bars indicate SD. $t$ test was used to test for a significant difference among pairs. Oneway ANOVA with Tukey's post hoc test was used to test for a significant difference among groups. Statistically significant $\left({ }^{*} P<0.05\right.$; ${ }^{* *} P<0.01$; $\left.{ }^{* * *} P<0.001\right)$ values are indicated. ns, not significant. Data shown in (A) are representative of three experiments conducted in triplicate with similar results. Data in (B, D, F-J) are representative of two experiments conducted in triplicate with similar results. Data in (C) are representative of five experiments conducted in triplicate with similar results. Data in (E) are representative of seven experiments conducted in triplicate with similar results. 


\section{ASM inhibition halts $A$. phagocytophilum vacuole maturation and expansion}

Because FIASMAs arrest $A$. phagocytophilum infection at a postbacterial binding step, we sought to identify the specific life cycle stage(s) affected. The A. phagocytophilum biphasic developmental cycle initiates when an infectious dense-core (DC) organism bound at the host cell surface enters via receptormediated endocytosis (Mott et al, 1999; Troese \& Carlyon, 2009). Within the first four $h$, the DC transitions to the noninfectious, replicative reticulate cell (RC) form and actively remodels its vacuole such that it avoids lysosomal fusion and becomes wrapped in vimentin intermediate filaments (Webster et al, 1998; Troese \& Carlyon, 2009; Truchan et al, 2016b). Over the next $24 \mathrm{~h}$, RCs divide within the inclusion as they expand in size, interface with organelles, and are decorated with secreted bacterial effector proteins (Troese \& Carlyon, 2009; Huang et al, 2010a, 2010b; Niu et al, 2012; Truchan et al, 2013, 2016b). RC to DC conversion occurs between 24 and $32 \mathrm{~h}$ followed by the release of infectious DC progeny between 28 and 36 h (Troese \& Carlyon, 2009).

We first examined whether functionally inhibiting ASM impedes A. phagocytophilum vacuole (ApV) maturation. Bacterial inclusions in infected RF/6A cells were assessed using confocal microscopy for the accumulation of vimentin, which is recruited early and remains irreversibly associated with the ApV for the entire infection cycle (Truchan et al, 2016b), and for the presence of APH0032, an A. phagocytophilum effector that is expressed and localizes to the ApV membrane during late-stage infection, between 20 and 32 h (Huang et al, 2010a; Oki et al, 2016). RF/6A cells were selected for this purpose because they are large and flat, enabling optimal imaging of the ApV (Munderloh et al, 2004; Sukumaran et al, 2011; Truchan et al, 2016c). In control cells, APH0032 was detected on an increasing percentage of ApVs at 20, 24, 28, and $32 \mathrm{~h}$ (Fig $2 \mathrm{~A}$ and B), suggesting that ApV maturation progressed normally. In desipramine-treated cells, however, pronouncedly fewer APH0032-positive ApVs were detected. Vimentin is associated with ApVs observed under both conditions (Fig 2A), indicating that this early ApV biogenesis event is not dependent on ASM activity. Indeed, a separate experiment verified that vimentin filaments wrap 100\% of ApVs in RF/6A cells irrespective of whether they are treated with DMSO or desipramine (Fig S1A and B). Consistent with desipramine being a reversible ASM inhibitor (Kornhuber et al, 2010), after the removal of the drug at $20 \mathrm{~h}$, the numbers of APH0032-positive ApVs began to significantly increase by $28 \mathrm{~h}$ compared with cultures that contained desipramine (Fig 2B). The inverse phenomenon was observed when desipramine was first added at $20 \mathrm{~h}$ postinfection, as the percentage of APH0032-positive ApVs did not increase and was significantly less than that for control cells beginning at $28 \mathrm{~h}$ (Fig 2C). ApV area increased throughout the time course in control cells, but not in desipraminetreated cells (Fig 2D). Similar to APH0032 ApV membrane localization (Fig 2A-C), desipramine's effect on ApV size was bacteriostatic, as removal or addition at $20 \mathrm{~h}$ enabled restoration or stagnation of ApV expansion by $24 \mathrm{~h}$, respectively (Fig $2 \mathrm{E}$ and $\mathrm{F}$ ). Overall, these data demonstrate that functional inhibition of ASM inhibits late-stage expansion and maturation of the ApV in a reversible manner.

\author{
Desipramine inhibits $A$. phagocytophilum infectious progeny \\ generation
}

ApV maturation, in terms of APH0032 localization to the ApV membrane, precedes A. phagocytophilum RC to DC conversion (Truchan et al, 2016c). FIASMA treatment reduces bacterial load and inhibits ApV maturation and expansion. Accordingly, we rationalized that desipramine impedes the production of infectious DC progeny. To test this hypothesis, HL-60 cells were exposed to desipramine or vehicle followed by infection with $A$. phagocytophilum. qRT-PCR was performed using the total RNA isolated at 24,28 , and $32 \mathrm{~h}$, the period during which RC to DC conversion occurs (Troese \& Carlyon, 2009), to measure transcript levels of aph1235, a DC-specific protein that contributes to A. phagocytophilum infectivity (Troese et al, 2011; Mastronunzio et al, 2012). An RC-unique marker has yet to be identified. A similar experiment was performed in parallel in which RF/6A cells treated with desipramine and incubated with $A$. phagocytophilum were screened for ApVs harboring APH1235-positive bacteria. As previously observed (Troese et al, 2011; Truchan et al, 2016c), both aph1235 expression and the number of ApVs harboring APH1235-positive bacteria increased throughout the time course for control cells (Fig $3 \mathrm{~A}-\mathrm{C}$ ). In desipramine-treated cells, aph1235 levels and ApVs containing APH1235-immunolabeled bacteria were pronouncedly reduced. To resolve whether the overall reduction in $A$. phagocytophilum load in desipramine-treated cells is specifically due to impairment of conversion to the infectious form and not due to a blockade in release of infectious progeny, infected desipraminetreated or control RF/6A cells were mechanically disrupted at $48 \mathrm{~h}$. Released bacteria were incubated with naive cells followed by immunofluorescence microscopic examination of infection $24 \mathrm{~h}$ later. The percentage of infected cells after incubation with $A$. phagocytophilum organisms recovered from desipramine-treated cells was eightfold lower than cells incubated with bacteria recovered from control cells (Fig 3D). These data confirm that functional inhibition of ASM inhibits A. phagocytophilum conversion to the infectious form.

\section{Desipramine halts the $A$. phagocytophilum infection cycle by inhibiting NPC1-mediated trafficking of cholesterol to the ApV}

Two lysosomal proteins, NPC1 and Niemann-Pick type C protein 2 (NPC2), cooperate to export cholesterol from lysosomes. NPC2 extracts and transfers cholesterol from the lysosomal internal membrane to NPC1, which aids in moving cholesterol from the limiting membrane to subcellular destinations via vesicular transport (Kuzu et al, 2017). Lysosomal accumulation of sphingomyelin resulting from deficiency or inhibition of ASM interferes with the ability of NPC2 to transfer cholesterol to NPC1, which, in turn, prevents NPC1-mediated transport of LDL cholesterol and its accumulation within lysosomes (Abdul-Hammed et al, 2010; Oninla et al, 2014; Kuzu et al, 2017). Given that A. phagocytophilum is dependent on the NPC1 pathway (Xiong \& Rikihisa, 2012), we directly assessed whether desipramine inhibits NPC1-mediated cholesterol trafficking to the ApV. Immunolabeled NPC1 was detected in close proximity to the ApV membrane and within the vacuole lumen associated with A. phagocytophilum organisms in vehicle 
A DMSO treatment
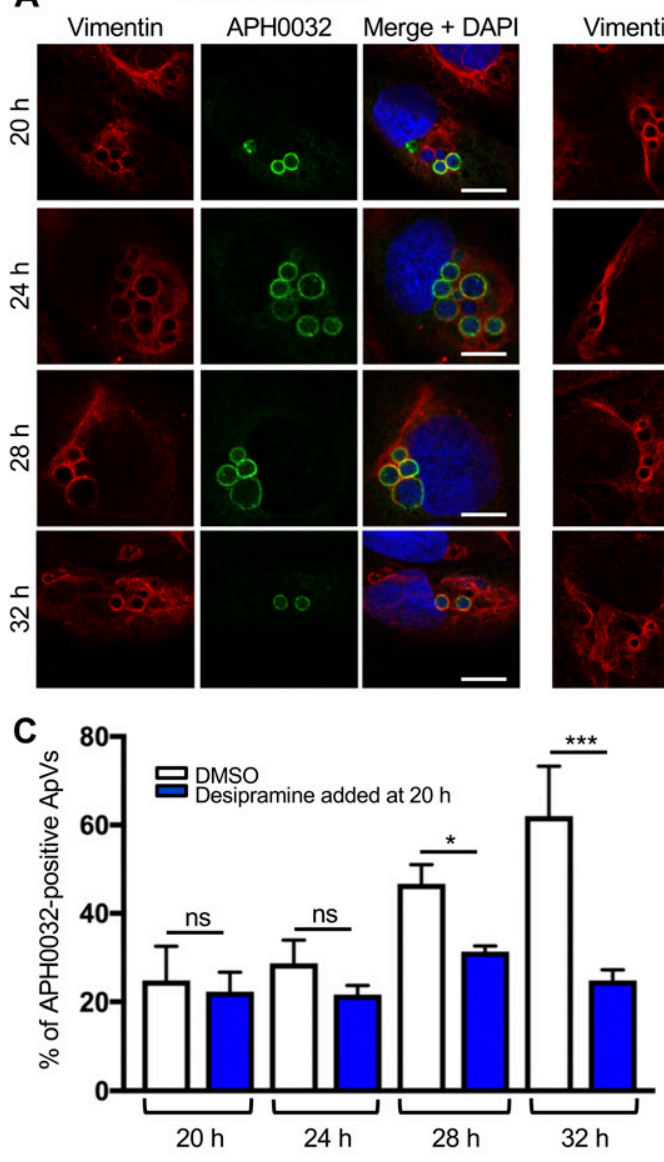

Desipramine treatment
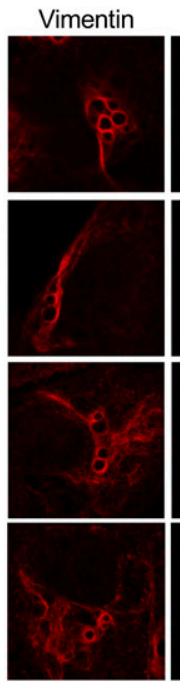

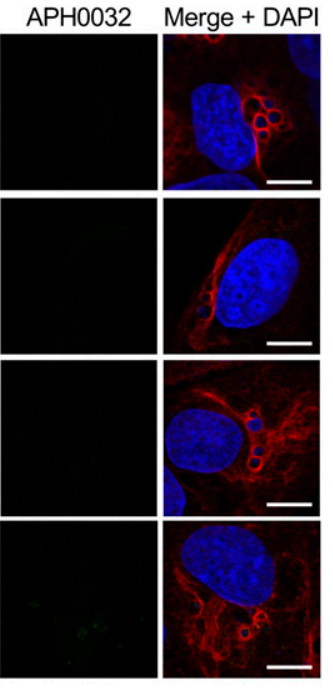

D
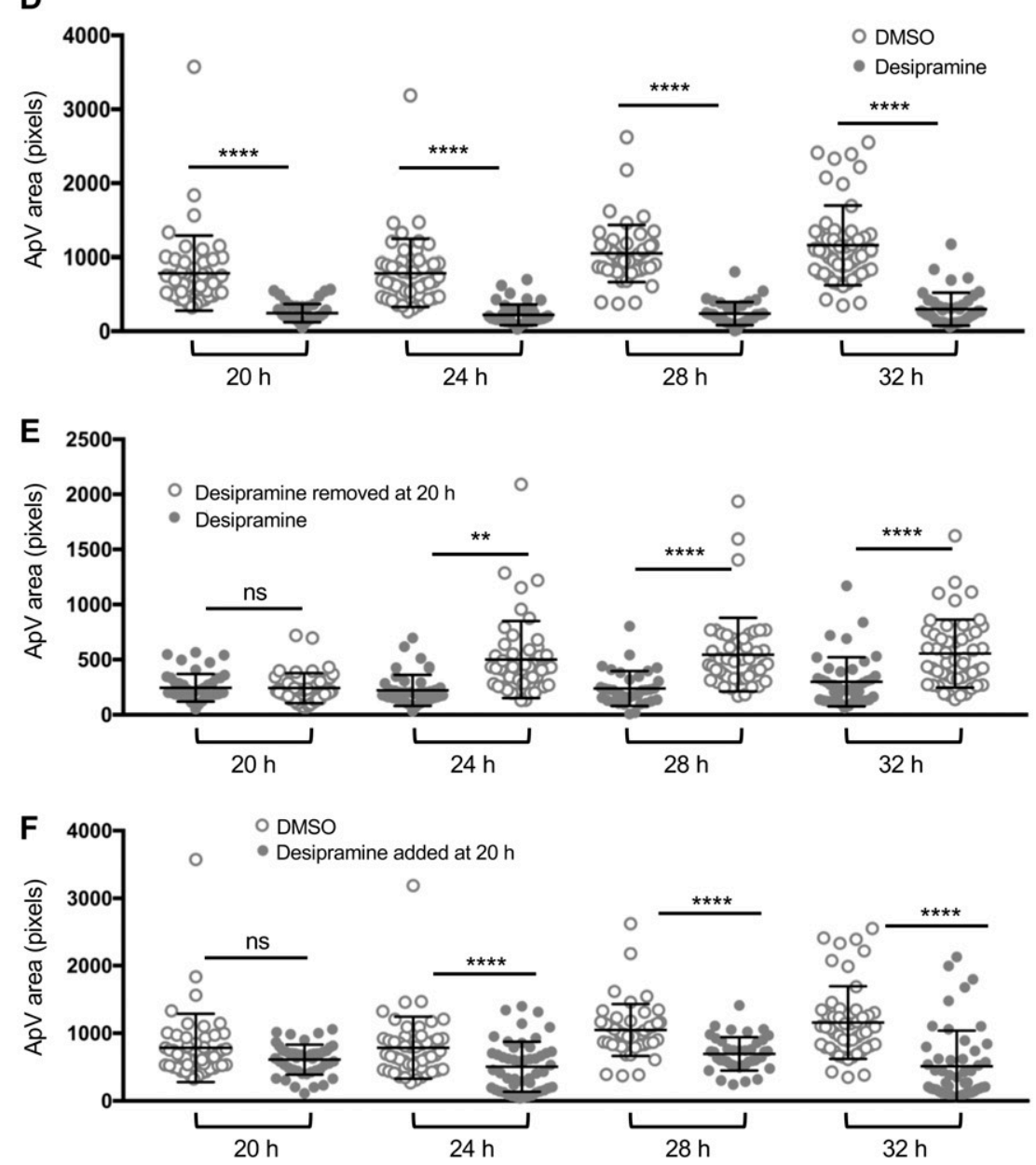

Figure 2. Functional inhibition of ASM halts ApV maturation and expansion.

(A, B, D, E) Desipramine was added to RF/6A cells before infection with A. phagocytophilum and treatment was either maintained throughout the time course (A, B, D) or removed at $20 \mathrm{~h}(\mathrm{~B}, \mathrm{E})$. (C, F) Desipramine was added to A. phagocytophilum-infected RF/6A cells beginning at $20 \mathrm{~h}$ (C, F). DMSO served as vehicle control. At 20, 24,28, and 32 $\mathrm{h}$, the cells were fixed and examined by confocal microscopy for ApV maturation (A-C) and expansion (D-F). (A-C) Desipramine reversibly inhibits APH0032 expression and localization to the ApV. A. phagocytophilum-infected RF/6A cells were screened with antibodies targeting vimentin and APH0032 to demarcate and assess maturation of the ApV, respectively. DAPI was used to stain host cell nuclei and bacterial DNA. (A) Representative confocal micrographs of desipramine or DMSO-treated cells at the 
A HL-60 cells

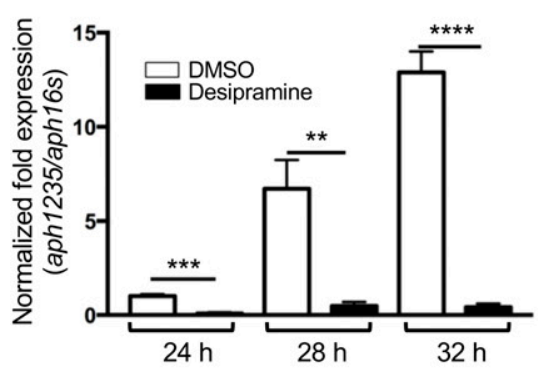

C RF/6A cells

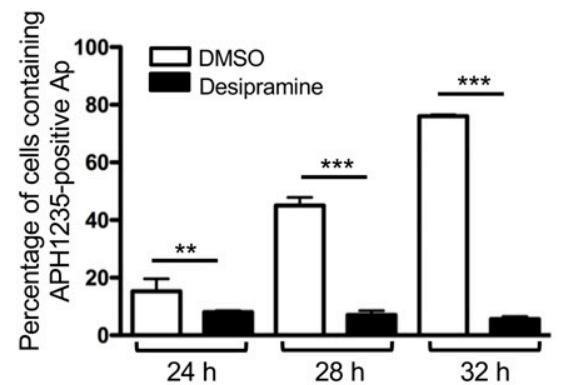

D RF/6A cells

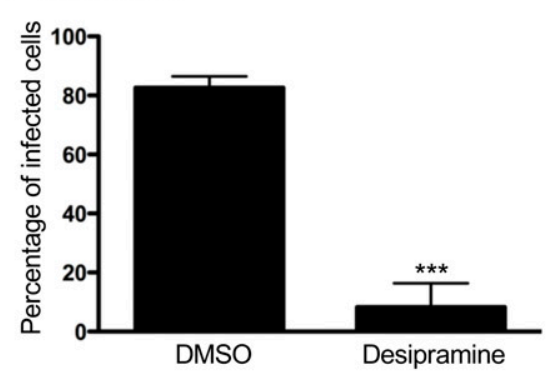

B RF/6A cells

DMSO treatment

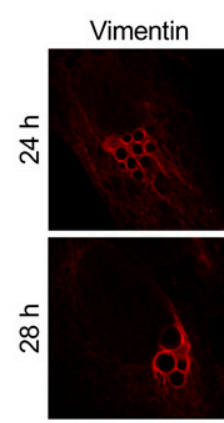

$\mathrm{APH} 1235$
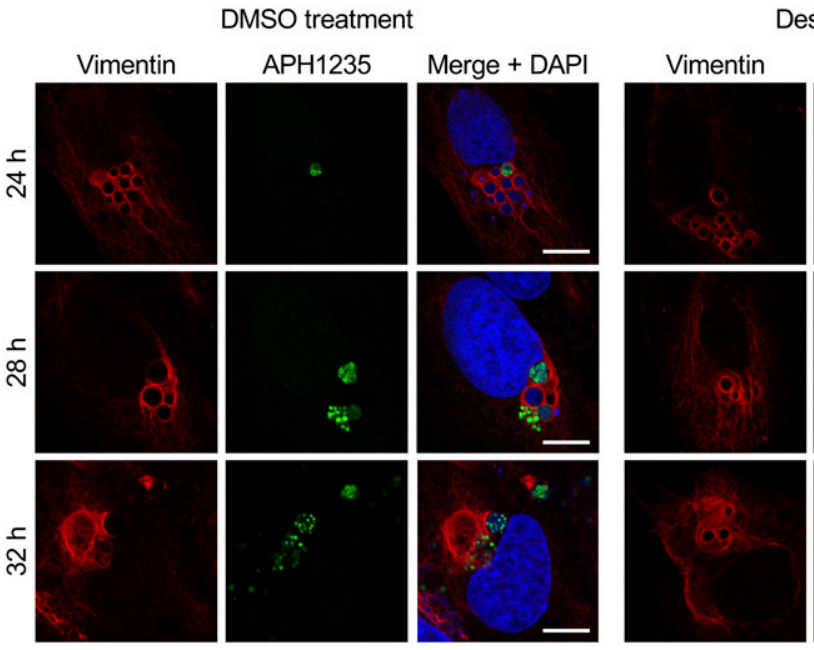

Desipramine treatment

Figure 3. Desipramine inhibits A. phagocytophilum conversion to the infectious form.

(A) Desipramine inhibits aph1235 transcription. Desipramine-treated HL-60 cells were infected with A. phagocytophilum. Total RNA isolated at 24 , 28, and 32 h was subjected to qRT-PCR. The $2^{-\triangle \Delta C T}$ method was used to determine the relative aph1235 expression level normalized to that of $A$. phagocytophilum $16 \mathrm{~S}$ rRNA. (B, C) Desipramine inhibits APH1235 protein expression. Desipramine-treated RF/6A cells were infected with A. phagocytophilum. At 24,28 , and 32 h, the cells were fixed, immunolabeled with APH1235 and vimentin antibodies, stained with DAPI, and visualized using confocal microscopy. (B) Representative confocal micrographs. Scale bar = $10 \mu \mathrm{M}$. (C) Percentage of APH1235-positive ApVs determined by counting 100 cells for each of triplicate samples per time point. (D) Desipramine inhibits A. phagocytophilum-infectious progeny production. RF/6A cells were treated with desipramine or DMSO followed by infection with A. phagocytophilum. At $48 \mathrm{~h}$, the cells were mechanically disrupted followed by isolation and subsequent incubation of host cell-free bacteria with naive untreated cells. At $24 \mathrm{~h}$, the recipient cells were fixed and examined by immunofluorescence microscopy to determine the percentage that had become infected. Error bars indicate SD. $t$ test was used to test for a significant difference among pairs. Statistically significant ( $\left.{ }^{* *} P<0.01 ;{ }^{* *} P<0.001 ;{ }^{* * *} \mathrm{P}<0.0001\right)$ values are indicated. Data shown in (A-C) are representative of three experiments conducted in triplicate that yielded similar results. Data shown in (D) are representative of two experiments conducted in triplicate with similar results.

control-treated RF/6A cells, but not in desipramine-treated cells (Fig 4A and B). A. phagocytophilum intracellular parasitism also involves hijacking Beclin-1 to induce autophagosome formation and rerouting ceramide-rich TGN46-positive trans-Golgi-derived vesicles to the ApV (Niu et al, 2012; Truchan et al, 2016c). Yet, desipramine had no effect on either of these phenomena (Fig S1C and D). Live cell imaging revealed that desipramine drastically reduced the percentage of ApVs with which BODIPY cholesterol-positive, but not BODIPY ceramide-positive vesicles associated (Fig 4C-E). Consistent with blocking cholesterol egress from lysosomes, desipramine induced the formation of numerous large BODIPY cholesterol-filled vesicles (Fig $4 \mathrm{C}$ ) that were confirmed to be
LysoTracker Red positive (Fig S1E). Thus, functional inhibition of ASM blocks A. phagocytophilum infection cycle progression by specifically interfering with bacterial acquisition of LDL cholesterol via the NPC1 pathway.

\section{ASM is essential for A. phagocytophilum to productively infect mice}

Because ASM activity is critical for A. phagocytophilum infection to progress in tissue culture cells, the relevance of ASM to infection in vivo was determined. Groups of WT or $\mathrm{ASM}^{-/-}$mice were inoculated with DC organisms followed by qPCR analyses of bacterial DNA load

indicated postinfection time points. (B, C) Percentages of APH0032-positive ApVs determined for 100 cells for each of three biological replicates per condition. (D-F) Desipramine reversibly inhibits ApV expansion. The mean ApV pixel area was determined for 50 ApVs per time point per condition. Error bars indicate SD. $t$ test was used to test for a significant difference among pairs. Statistically significant $\left({ }^{*} P<0.05 ;{ }^{* *} P<0.01 ;{ }^{* * *} P<0.001 ;{ }^{* * *} P<0.0001\right)$ values are indicated. ns, not significant. Data shown are representative of three experiments conducted in triplicate with similar results. Scale bar $=10 \mu \mathrm{m}$. 
A Vimentin
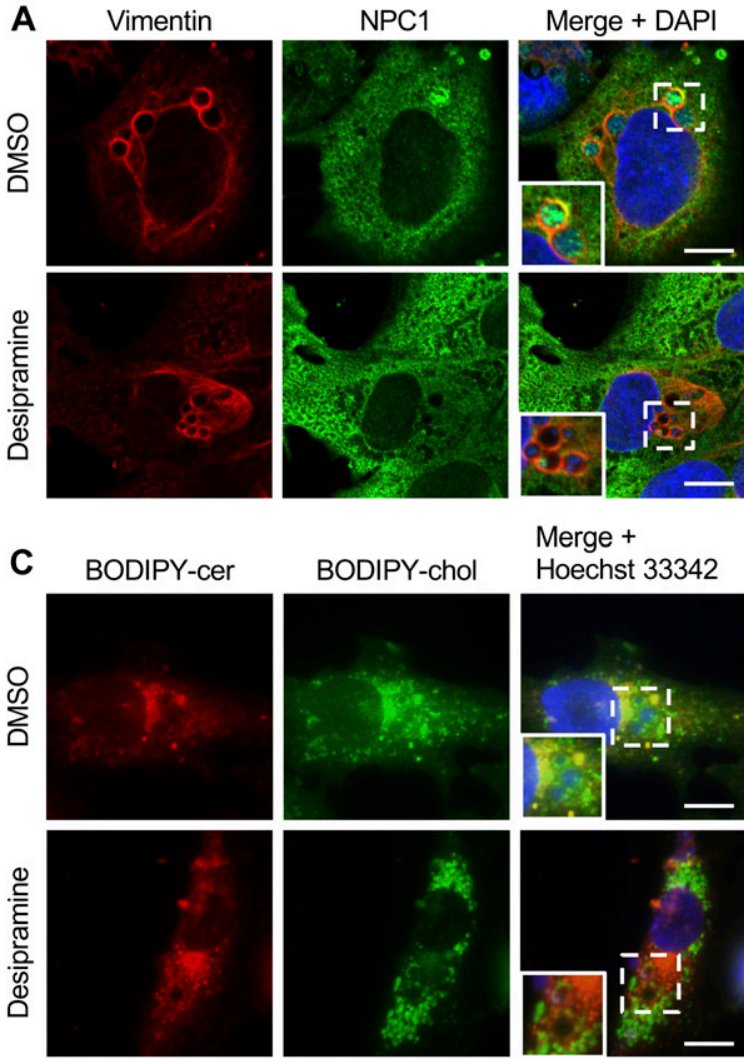

Merge +

Hoechst 33342
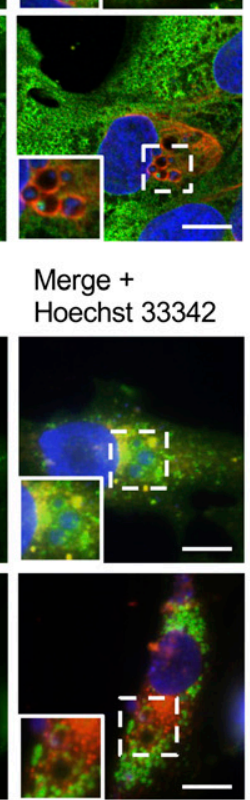

B

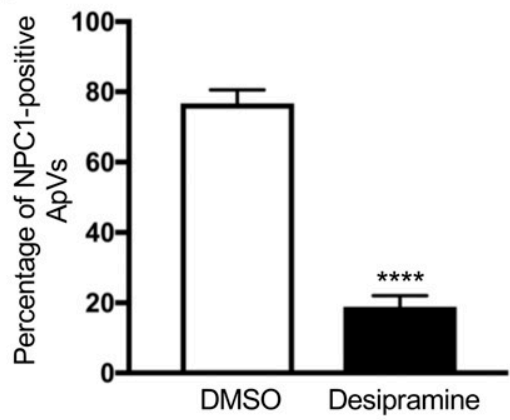

D

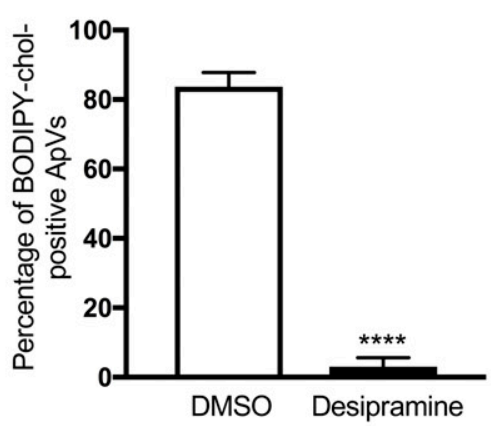

E

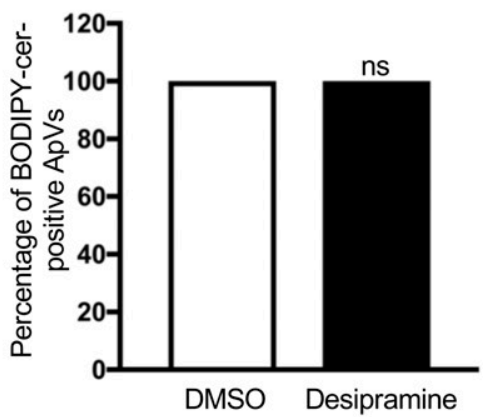

Figure 4. Desipramine alters NPC1-mediated cholesterol trafficking to the ApV.

Desipramine treatment inhibits NPC1 localization to the ApV. Desipramine- or DMSO-treated RF/6A cells were infected A. phagocytophilum. (A-E) At 24 h, the cells were either fixed, immunolabeled with vimentin and NPC1 antibodies, stained with DAPI, and examined by confocal microscopy (A, B); or incubated with BODIPY ceramide (cer) or BODIPY cholesterol (chol), stained with Hoechst 33342, and visualized by live cell imaging (C-E). (A) Representative confocal micrographs of infected cells immunolabeled for vimentin and NPC1. Regions that are demarcated by hatched-line boxes are magnified in the inset panels. (B) Percentage of vimentin-positive ApVs to which NPC1 immunosignal localizes in DMSO- and desipramine-treated cells determined by counting 100 cells for each of triplicate samples per condition. (C) Representative live cell images of infected cells incubated with BODIPY-cer and BODIPY-chol. (D, E) Percentages of ApVs to which BODIPY-cer-positive (D) or BODIPYchol-positive (E) vesicles localize. Error bars indicate SD. $t$ test was used to test for a significant difference among pairs. Statistically significant ( $\star \star \star \star P<0.001)$ values are indicated. ns, not significant. Data shown are representative of three experiments conducted in triplicate that yielded similar results. Scale bar $=10 \mu \mathrm{m}$.

in the peripheral blood. The A. phagocytophilum load in WT mice peaked by day 16 and gradually subsided to an undetectable level by day 28 (Fig 5A). In ASM ${ }^{-/-}$mice, however, bacterial DNA was barely detectable at any time point. To assess desipramine's ability to reduce bacterial burden in an active infection, WT mice were inoculated with A. phagocytophilum followed by injection with either desipramine or vehicle on days 7 through 12 at a dosage confirmed to inhibit ASM activity in vivo and within the range approved for use in humans (Teichgraber et al, 2008; Hayasaka et al, 2015). Strikingly, although infection proceeded normally in vehicle-treated mice, the A. phagocytophilum burden was drastically reduced on days 8 and 12 and no longer detectable beginning on day 16 in desipraminetreated mice (Fig 5B). These data confirm that ASM is critical for and demonstrate the ability of desipramine to eliminate $A$. phagocytophilum infection in vivo.

\section{Desipramine-induced cholesterol accumulation in the $C$. burnetii parasitophorous vacuole is bactericidal}

To investigate whether desipramine's efficacy in inhibiting infection could be extended to other intracellular bacteria that interface with
LDL cholesterol trafficking pathways, we next focused on C. burnetii, which causes $Q$ fever. Whereas acute $Q$ fever is typically selflimiting, chronic disease requires at least 18 mo of antibiotic therapy. C. burnetii first infects alveolar macrophages during natural infection, but can be found in a wide range of cell types. Inside the host cell, C. burnetii directs formation of a large, lysosome-like vacuole called the Coxiella-containing vacuole (CCV) (Kohler \& Roy, 2015). Although cholesterol, including LDL-derived cholesterol, readily traffics to the CCV, C. burnetii is sensitive to cholesterol levels in the CCV membrane, with elevated cholesterol leading to increased acidification and bacterial degradation (Mulye et al, 2017). Furthermore, C. burnetii is sensitive to drugs that perturb host cholesterol homeostasis and grows poorly in NPC1-deficient cells (Czyz et al, 2014; Howe \& Heinzen, 2006). Given the sensitivity of C. burnetii to cholesterol, we tested the effect of desipramine on $C$. burnetii growth in THP-1 macrophage-like cells. Desipraminetreated or untreated control cells were incubated with transgenic C. burnetii constitutively expressing mcherry. Cells were cultivated in the continued presence of drug or vehicle and fluorescence levels measured daily as an indication of bacterial growth. Beginning on day 3 , the first day on which there was any detectable 

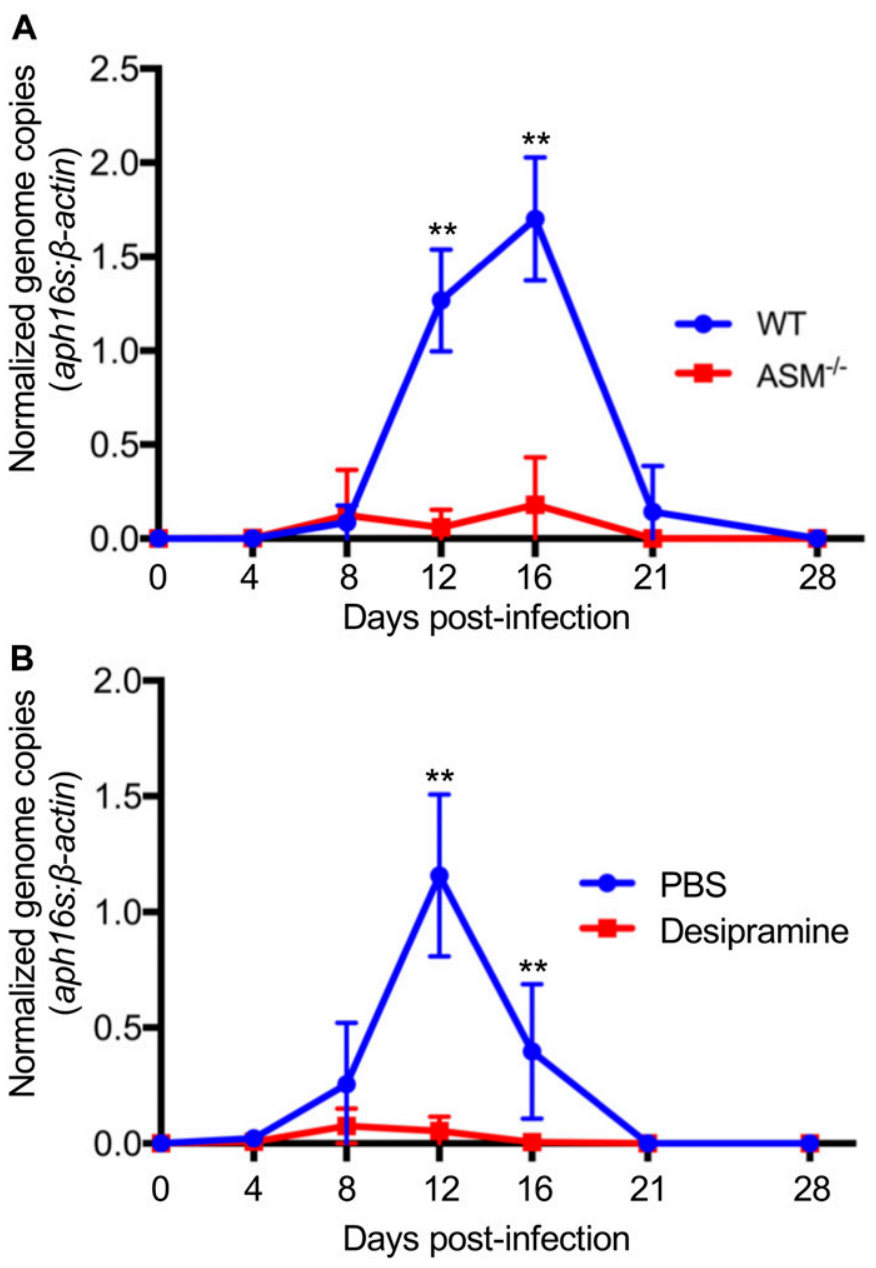

Figure 5. ASM is essential for A. phagocytophilum to productively infect mice. (A) A. phagocytophilum fails to productively infect $\mathrm{ASM}^{-1-}$ mice. (A) $\mathrm{ASMase}^{-1-}$ mice or WT mice were infected with A. phagocytophilum DC organisms. Peripheral blood drawn on days $4,8,12,16,21$, and 28 d postinfection was analyzed by qPCR. Relative levels of the A. phagocytophilum 16S rRNA gene were normalized to those of $\beta$-actin using the $2^{-\Delta \Delta C T}$ method. (B) Desipramine reduces the A. phagocytophilum DNA load in the peripheral blood when administered to infected mice. A. phagocytophilum-infected WT mice were administered desipramine or PBS on days 7 through 12 postinfection, and the bacterial DNA load in the peripheral blood was determined using qPCR. Error bars indicate SD. $t$ test was used to test for a significant difference among pairs. Statistically significant $\left({ }^{* *} P<0.01\right)$ values are indicated. Data shown in (A) are representative of eight experiments each of which were conducted with 5-7 mice per group. Data shown in (B) are representative of three experiments each of which were conducted with 5-7 mice per group.

increase in fluorescence signal, mCherry-C. burnetii proliferation was significantly inhibited in desipramine-treated cells (Fig 6A). Importantly, desipramine failed to alter mCherry-C. burnetii growth in axenic medium (Fig 6B), indicating that its inhibitory effect is restricted to the intracellular niche. To determine whether desipramine's action on the pathogen was bacteriostatic or bactericidal, C. burnetii was allowed to infect HeLa cells and MH-S murine alveolar macrophages treated with desipramine or DMSO. Cells were harvested every $48 \mathrm{~h}$ to determine the number of viable bacteria using a colony-forming unit (CFU) assay (Clemente et al, 2018). In control HeLa cells, a fourfold increase in bacterial load was observed, whereas the number of viable C. burnetii decreased over time in desipramine-treated cells (Fig 6C). Comparable results were observed in $\mathrm{MH}-\mathrm{S}$ macrophages (Fig 6D), suggesting that desipramine is bactericidal to C. burnetii.

Similar to A. phagocytophilum, C. burnetii undergoes a biphasic developmental cycle. The environmentally stable but nonreplicative small-cell variant infects cells through phagocytosis, and the bacteria-containing phagosome matures through the default endocytic pathway to a phagolysosome. Over the next 24-48 $\mathrm{h}$, bacteria reside in the tight-fitting phagolysosome and transition to the replicative large-cell variant. Around $48 \mathrm{~h}$, the CCV expands through fusion with host endosomal compartments and autophagosomes, allowing bacterial replication (Kohler \& Roy, 2015). To define the stage of the $C$. burnetii intracellular life cycle that is desipramine sensitive, we added the drug at 24-h intervals after infection and determined bacterial numbers after $6 \mathrm{~d}$. C. burnetii was sensitive to desipramine only in the first $48 \mathrm{~h}$ after infection (Fig $6 \mathrm{E})$, suggesting that inhibiting ASM affects an early stage of $C$. burnetii infection before CCV expansion. This result is further supported by the observation that CCVs in desipramine-treated cells did not expand, based on CCV size at 6 d postinfection (Fig 6F).

Previous experiments demonstrated that blocking cholesterol export from late endosomes/lysosomes with U18666A increased cholesterol in the CCV, leading to acidification and bacterial death (Mulye et al, 2017). To determine if functionally inhibiting ASM increases CCV cholesterol levels, we labeled infected cells with filipin, a fluorescent cholesterol-binding compound. As observed previously (Howe \& Heinzen, 2006; Mulye et al, 2017), filipin labeled the CCV membrane in control cells (Fig 6G), indicating the CCV contains cholesterol or other sterols. However, upon desipramine treatment, the intensity of filipin labeling in the CCV increased, confirming that ASM inhibition elevates CCV cholesterol levels. Together, these data suggest that blocking ASM activity kills $C$. burnetii by increasing CCV cholesterol levels.

\section{Chlamydiae do not demonstrate the same degree of sensitivity to desipramine as $A$. phagocytophilum and $C$. burnetii}

Given that the exquisite sensitivities of A. phagocytophilum and $C$. burnetti to desipramine are linked to interactions with LDL cholesterol in the NPC1 pathway, we examined whether the drug could effectively target obligate intracellular bacteria whose growth is not exclusively dependent on LDL cholesterol. C. trachomatis, a leading cause of sexually transmitted disease and infectious blindness, obtains LDL-derived and de novo-synthesized cholesterol by intercepting exocytic traffic from the Golgi (Carabeo et al, 2003). C. trachomatis also recruits cholesterol-rich multivesicular bodies (MVBs) and high-density lipoprotein biogenesis proteins involved in cholesterol efflux to its inclusion for growth (Beatty, 2006, 2008; Cox et al, 2012). To determine if desipramine alters C. trachomatis infection, desipramine-treated and control HeLa cells were infected with C. trachomatis serovar L2 for 28-30 h. Infected cells were either fixed to verify equal infection across conditions or lysed. The lysates were serially diluted and plated onto fresh monolayers, which were assessed for inclusion-forming units at $24 \mathrm{~h}$ postinfection. Desipramine treatment throughout the chlamydial developmental cycle resulted in biologically irrelevant, albeit 
A THP-1 cells

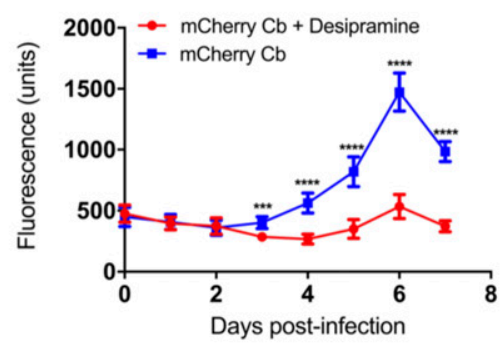

C HeLa cells

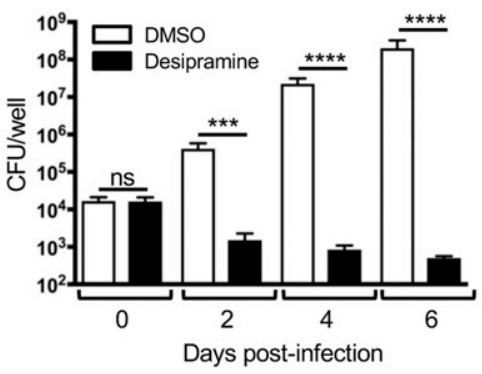

E HeLa cells

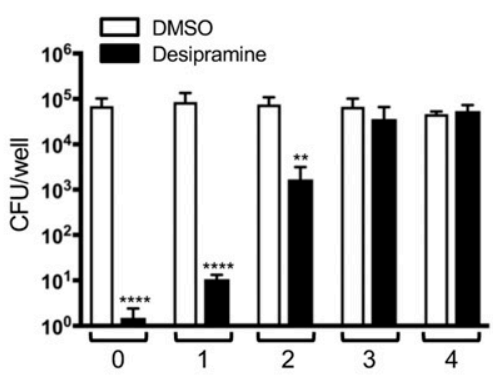

Days desipramine added post-infection

\section{B Axenic medium}

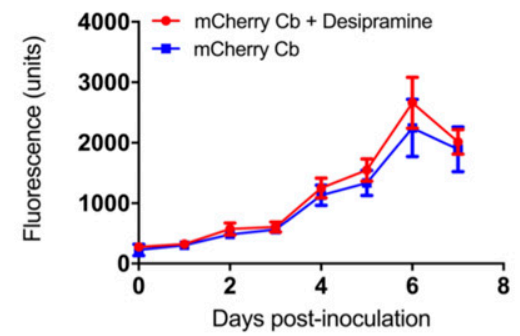

D $\mathrm{MH}-\mathrm{S}$ cells

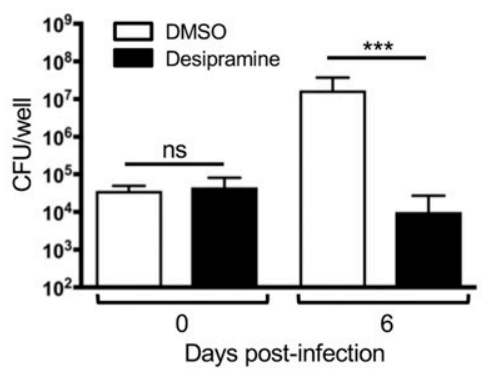

F HeLa cells

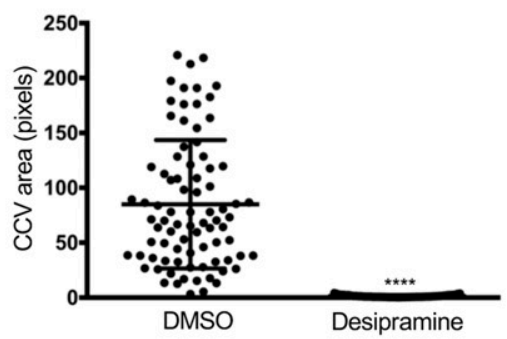

Figure 6. Desipramine-induced cholesterol accumulation in the $C$. burnetii vacuole is bactericidal. (A, B) mCherry-C. burnetii (Cb)-infected THP-1 macrophage-like cells (A) or mCherry-C. burnetii grown in axenic medium (B) were treated with desipramine or not treated with. The bacterial load was measured as relative fluorescent units. (C-E) C. burnetii was added to HeLa cells (C, E) or MH-S cells (D) that had been pretreated with desipramine or DMSO, or C. burnetii-infected cells were treated at the indicated days postinfection (E). Bacterial load was measured using a CFU assay. (F) CCV area was determined for desipramine and DMSO-treated C. burnetii-infected HeLa cells. (G) HeLa cells that had been treated with

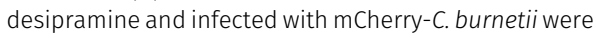
labeled with filipin and CD63 antibody. Error bars indicate SD. $t$ test was used to test for a significant difference among pairs. Statistically significant $\left({ }^{* *} P<\right.$ $0.01 ; * * * P<0.001 ; * * * * P<0.0001$ ) values are indicated. ns, not significant. Data in panels $A$ and $B$ are representative of three experiments conducted in triplicate with similar results. Data in panels $\mathrm{C}$ through $\mathrm{F}$ are the means \pm SD of three independent experiments. Scale bar $=50 \mu \mathrm{m}$

G HeLa cells
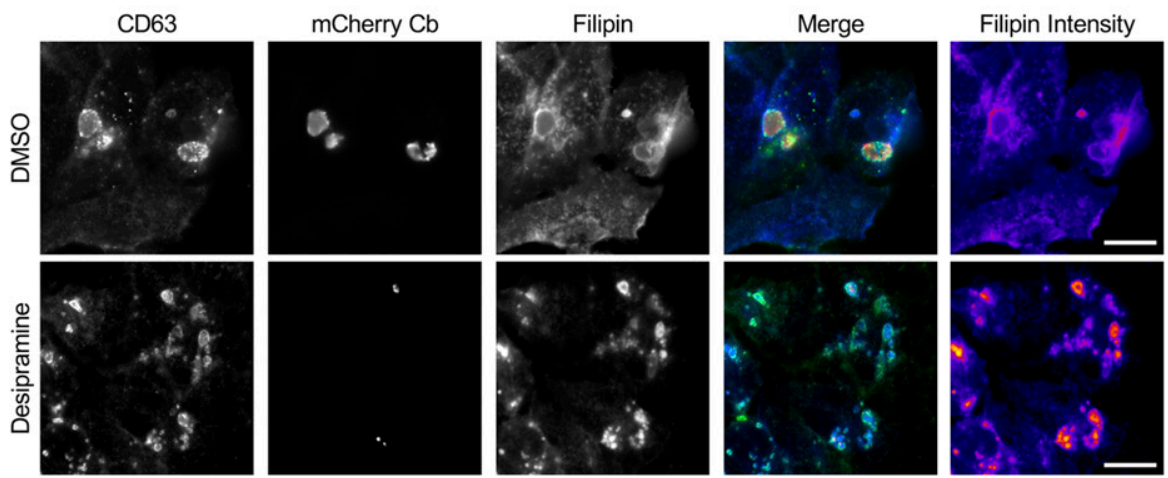

statistically significant declines in infectious progeny production and inclusion size (Fig 7A and B).

As the $C$. trachomatis serovar $\mathrm{L} 2$ growth rate is relatively fast, with the developmental cycle completed by $48 \mathrm{~h}$ (Abdelrahman \& Belland, 2005), it can outgrow and/or compensate for certain nutritional stresses (Ouellette et al, 2018). Accordingly, desipramine sensitivity was tested on the slower growing species C. pneumoniae, a respiratory pathogen and cause of atherosclerosis that produces infectious progeny by $84 \mathrm{~h}$ (Wolf et al, 2000). Laboratory culture of $C$. pneumoniae is fastidious, which can render assessing alterations in drug treatment and infectivity of primary infection difficult. To eliminate the possibility of desipramine pretreatment inhibiting $C$. pneumoniae entry, HeLa cells were first infected with C. pneumoniae, and then desipramine or vehicle was added $2-3 \mathrm{~h}$ postinfection. Infectious progeny production was measured at 53 and $73 \mathrm{~h}$ postinfection. C. pneumoniae progeny production was highest late in the 
A C. trachomatis

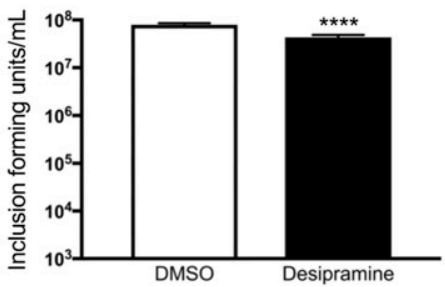

C C. pneumoniae

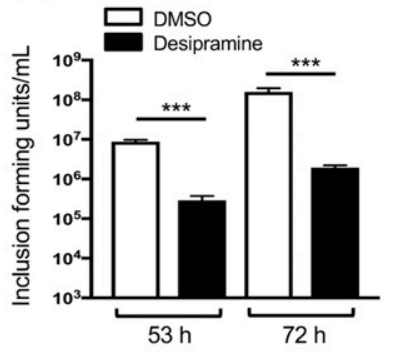

E C. trachomatis
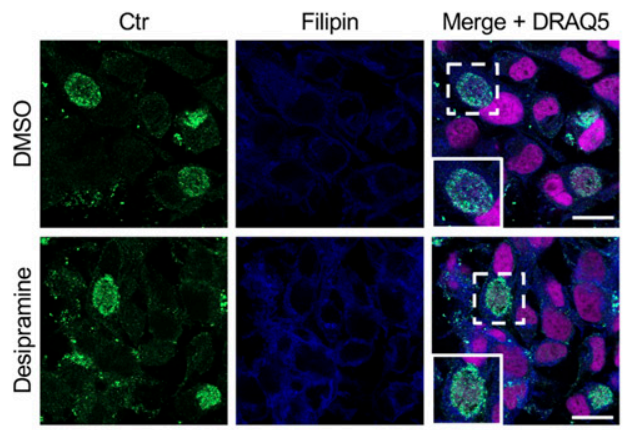

G C. trachomatis

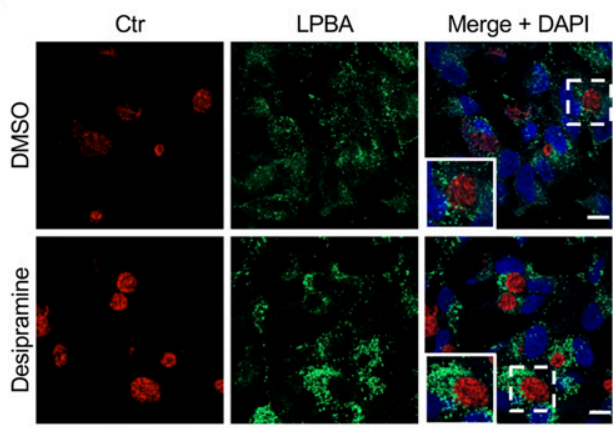

I C. trachomatis

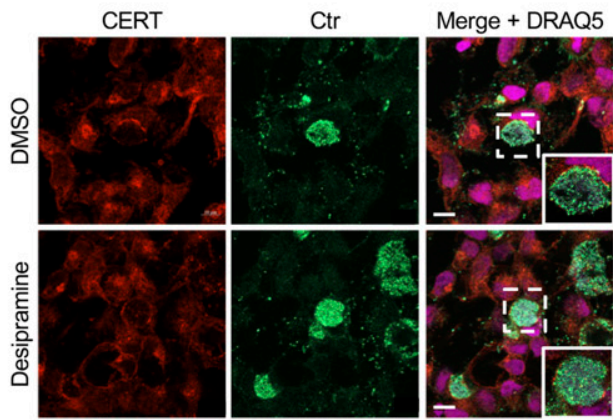

B C. trachomatis

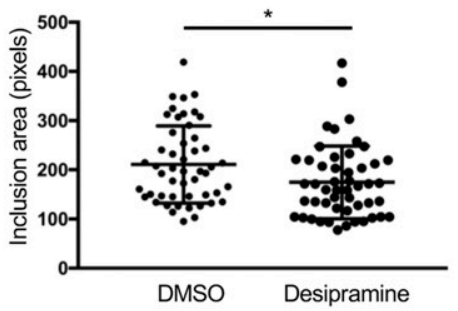

D C. pneumoniae

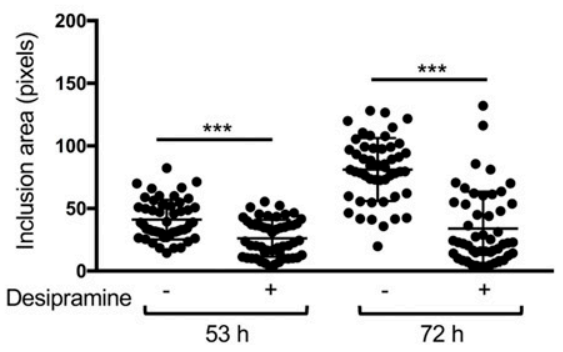

F C. pneumoniae
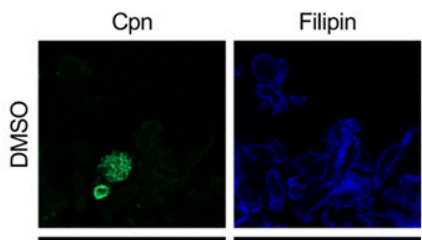

Merge + DRAQ5

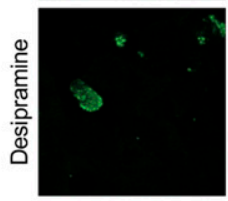

H C. pneumoniae

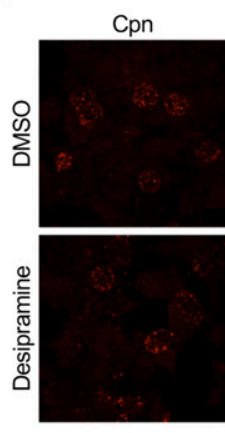

J

J C. pneumoniae

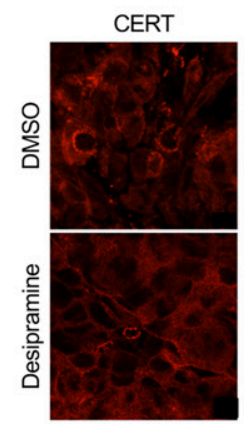

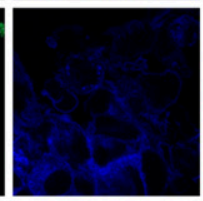

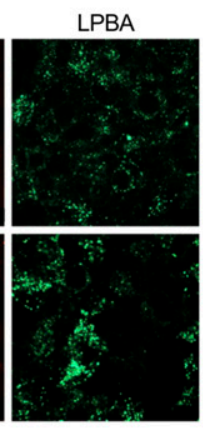

Merge + DAPI
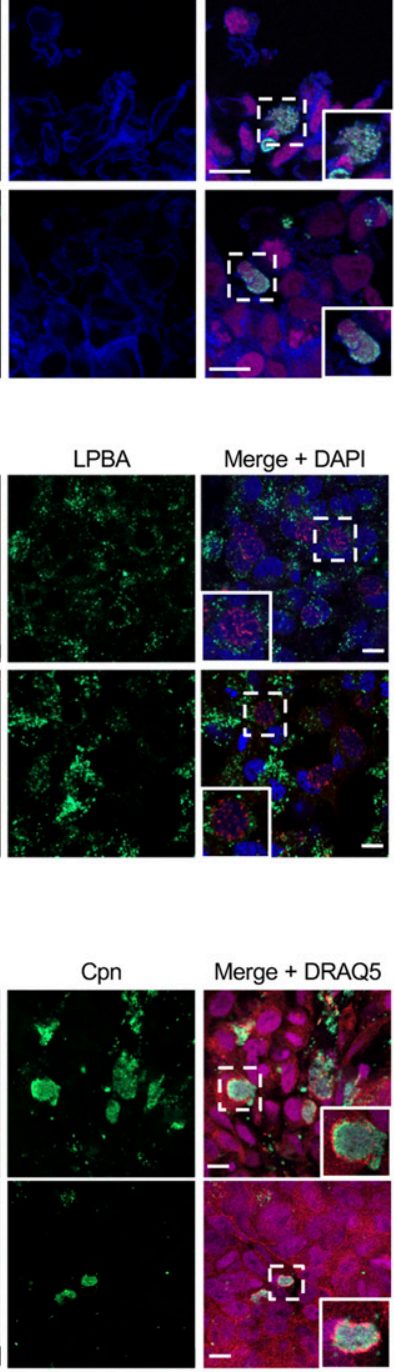

Merge + DRAQ5

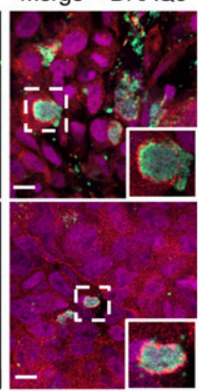

Figure 7. C. trachomatis and $C$ pneumoniae exhibit reduced FIASMA sensitivity.

(A-D) Desipramine or DMSO-treated HeLa cells infected with $C$. trachomatis (Ctr; A, B) or C. pneumoniae (Cpn; C, D) were either lysed to recover infectious progeny that were incubated with naive HeLa cells to determine inclusionforming units $(A, C)$ or were fixed and assessed by immunofluorescence microscopy to determine inclusion area $(B, D)$. (E-J) Desipramine-treated or control cells were infected with $\mathrm{Ctr}$ ( $\mathrm{E}, \mathrm{G}$ I) or $\mathrm{Cpn}(\mathrm{F}, \mathrm{H}, \mathrm{J})$. The cells were either incubated with filipin (E, F) or screened with antibodies specific for LBPA $(G, H)$ or $\operatorname{CERT}(\mathrm{I}, \mathrm{J})$ together with antisera against C. trachomatis (E, G, I) or C. pneumoniae $(\mathrm{F}, \mathrm{H}, \mathrm{J})$. DAPI or DRAQ5 was used to stain DNA. Regions that are demarcated by hatched-line boxes are magnified in the inset panels. Error bars indicate SD. $t$ test was used to test for a significant difference among pairs. Statistically significant $\left({ }^{\star} P<0.05 ;{ }^{* \star *} P<0.001\right)$ values are indicated. Data shown are representative of three experiments conducted in triplicate with similar results. Scale bar $=10 \mu \mathrm{m}$ 
developmental cycle, as illustrated by an almost two-log increase in inclusion-forming units recovered from control cells at $72 \mathrm{~h}$ versus 53 h (Fig 7C). In contrast, desipramine significantly reduced infectious progeny production by 1.5 log. Moreover, there was only a $15 \%$ increase in progeny production between 53 and $72 \mathrm{~h}$ in desipraminetreated cells compared with a $56 \%$ increase between these time points in control cells. These data correlate with decreases of approximately $35 \%$ in the inclusion area for desipramine-treated versus control cells (Fig 7D). Thus, desipramine effectively inhibits C. pneumoniae, but not $C$. trachomatis, infection.

Because the negative impact of desipramine on $C$. pneumoniae was not as severe as for A. phagocytophilum and C. burnetii, and the drug had no biologically significant effect on C. trachomatis, we evaluated the hypothesis that desipramine does not interfere with chlamydial inclusion interactions with the Golgi and MVBs, which, in turn, allows cholesterol delivery to inclusions even when its egress from lysosomes is blocked. Hence, these phenomena were assessed in desipramine-treated and control cells infected with $C$. trachomatis for $24 \mathrm{~h}$ or C. pneumoniae for $53 \mathrm{~h}$. In accordance with ASM inhibition causing cholesterol to accumulate in lysosomes, desipramine-treated cells displayed vesicle-like structures heavily labeled with filipin (Fig 7E and F). No difference in filipin labeling of chlamydial inclusions was observed. Similar results were noted for lysobisphosphatidic acid (LPBA), an MVB marker that localizes to C. trachomatis inclusions (Beatty, 2006, 2008). In desipramine-treated cells, LPBA immunolabeling increased in a similar manner to that observed for cholesterol (Fig 7G and H). LPBA pooled around the inclusions harboring C. trachomatis, as previously reported (Beatty, 2006, 2008), and C. pneumoniae, observed here for the first time, and did so whether or not the cells were exposed to desipramine. ASM inhibition also had no effect on chlamydial recruitment of VAMP4 and syntaxin 6 (Fig S2), two Golgi-derived soluble $\mathrm{N}$-ethylmalemide-sensitive factor attachment protein receptors that localize to C. trachomatis and C. pneumoniae inclusions (Moore et al, 2011; Kabeiseman et al, 2013).

Finally, we examined whether localization of ceramide transfer protein (CERT) to inclusions is desipramine-sensitive. CERT, which mediates ER-to-Golgi transfer of ceramide, is recruited to the $C$. trachomatis inclusion membrane, where it contributes to the generation of sphingomyelin, which is important for chlamydial growth (Derre et al, 2011; Elwell et al, 2011). CERT localization to inclusions of both chlamydial species was unhindered by desipramine (Fig 71 and J). This observation marks the first report of CERT being recruited to $C$. pneumoniae inclusions. Altogether, these data demonstrate that the infection cycles of $C$. trachomatis and C. pneumoniae are less susceptible to pharmacologic inhibition of ASM than A. phagocytophilum or C. burnetii, which is due, at least in part, to the abilities of these bacteria to hijack cholesterol from the Golgi and MVBs and to parasitize other lipids such as sphingomyelin.

\section{Discussion}

In this study, we demonstrate that FIASMAs, which are FDA approved, licensed for medical use, exhibit low toxicity, and are suited for prolonged treatment (Kornhuber et al, 2010), reduce host cell infection by four obligate intracellular vacuole-adapted bacteria by blocking LDL cholesterol trafficking from the lysosome. Intracellular pathogens are difficult to target with most conventional antibiotics. Although tetracyclines and fluoroquinolones are usually effective, the occurrence of intracellular bacterial resistance and the drugs' use being contraindicated in certain circumstances warrants development of novel antimicrobial therapies. Finding new therapeutic indications for FDA-approved compounds that disrupt eukaryotic pathways commonly targeted by intracellular bacteria can accelerate drug discovery on this front.

ASM inhibition is most effective against two of the model intracellular bacterial pathogens examined herein, A. phagocytophilum and $C$. burnetii, through distinct mechanisms. Desipramine prevents NPC1 trafficking of LDL cholesterol to the ApV, which reversibly blocks inclusion expansion and maturation as well as $A$. phagocytophilum replication and infectious progeny generation. This negative effect was confirmed for two additional FIASMAs and specifically linked to inhibition of ASM, rather than acid ceramidase. Desipramine exerts bacteriostatic action on A. phagocytophilum not only when added before, but also when added after bacterial entry, demonstrating the ability to halt active infection. Importantly, this phenomenon is recapitulated in vivo, as the bacterium cannot productively infect ASMdeficient mice or WT mice treated with desipramine within the range approved for human use (Hayasaka et al, 2015).

In addition to intercepting the NPC1 pathway to obtain cholesterol, A. phagocytophilum hijacks the Beclin 1-Atg14L autophagy initiation pathway, likely to obtain autophagy-derived amino acids, and TGN exocytic vesicles (Niu et al, 2012; Truchan et al, 2016c). Desipramine inhibits infection, yet Beclin 1, TGN46, and BODIPY ceramide associated with the ApV in treated cells. Thus, although the bacterium's autophagy and TGN parasitism are mutually exclusive from cholesterol acquisition, the latter appears to be most critical for infection cycle progression. Moreover, we previously reported that TGN parasitism is essential for A. phagocytophilum transition from noninfectious RCs to infectious DCs (Truchan et al, 2016c). However, the present study reveals that RC-to-DC transition only occurs if NPC1-mediated cholesterol trafficking is not blocked. In the NPC1 pathway, a considerable portion of LDL cholesterol is transported first to the TGN before arrival at the ER, and the TGN is depleted of cholesterol in Niemann-Pick disease (Urano et al, 2008). Thus, desipramine could prevent A. phagocytophiluminfectious progeny generation directly by blocking cholesterolladen NPC1 vesicle delivery to the ApV and indirectly by blocking NPC1 vesicle delivery to the TGN, which, in turn, would culminate in TGN vesicles that are rerouted to the ApV being devoid of cholesterol.

C. burnetii is sensitive to cholesterol levels in the CCV, with increased cholesterol further acidifying the vacuole and degrading bacteria (Mulye et al, 2017). Inhibiting ASM with desipramine raises CCV cholesterol levels to kill C. burnetii in macrophages and epithelial cells. However, consistent with previous studies using U18666A (Mulye et al, 2017), C. burnetii is only sensitive during the first $48 \mathrm{~h}$, which, because the pathogen inhabits a tight-fitting vacuole during the first 24-48 h (Kohler \& Roy, 2015), suggests that once the CCV is established and C. burnetii is actively growing, either cholesterol no longer has an antimicrobial impact or the bacteria combat the negative effects. Regardless, FIASMAs have 
therapeutic potential against Q fever because C. burnetii would presumably be susceptible during the early stage of each infection cycle. This potential could extend to other drugs that perturb cholesterol homeostasis, as a recent screen of FDA-approved compounds showed that 57 of 62 tested completely inhibited C. burnetii growth, although their mechanisms of action, whether they are bacteriostatic or bactericidal, and whether they are effective during a specific $C$. burnetii infection stage was not determined (Czyz et al, 2014). As demonstrated for both A. phagocytophilum and C. burnetii, desipramine's antimicrobial efficacy was due exclusively to its ability to promote lysosomal cholesterol sequestration and not a direct effect on either bacterium, suggesting that FIASMAs would likely be invulnerable to the development of pathogen resistance.

Compared with A. phagocytophilum and C. burnetii, desipramine was less effective against $C$. pneumoniae and even less so against $C$. trachomatis because of chlamydial utilization of not only LDL-, but also non-LDL cholesterol sources and sphingomyelin to fuel intracellular growth. C. pneumoniae infections can be persistent, with symptoms often reappearing after a short or conventional course of antibiotics (Burillo \& Bouza, 2010). The ability of desipramine to reduce the $C$. pneumoniae load by 1.5 orders of magnitude in vitro suggests that combination drug therapy consisting of an antibiotic plus a FIASMA warrants consideration as an approach to minimize recalcitrant $C$. pneumoniae infections.

Because the susceptibilities of the vacuole-adapted bacteria examined herein to ASM inhibition are linked to sensitivities to lysosomal sequestration of LDL cholesterol, it is reasonable to posit that the antimicrobial efficacy of FIASMAs could be extended to combat other LDL cholesterol-dependent pathogens. Ehrlichia chaffeensis, like A. phagocytophilum, becomes more infectious when unesterified cholesterol is incorporated into the bacterial cell envelope (Lin \& Rikihisa, 2003). As LDL cholesterol only becomes esterified once trafficked to the ER by the NPC1 pathway (Walpole et al, 2018), E. chaffeensis presumably intercepts this pathway and would, therefore, be FIASMA sensitive. Similarly, the apicomplexan parasite, Toxoplasma gondii, actively intercepts LDL cholesterol, cannot grow in NPC-deficient fibroblasts, and exhibits stunted development in U18666A-treated cells (Coppens et al, 2000). Brucella abortus intracellular replication is fairly insensitive to drugs that alter cholesterol homeostasis, but the pathogen requires plasma membrane cholesterol to invade macrophages and cannot infect NPC1 knockout mice (Watarai et al, 2002; Czyz et al, 2014). It is tempting to question whether individuals who are heterozygous for ASM mutations that negatively affect enzymatic activity exhibit resistance to infection by intracellular pathogens that require LDL cholesterol.

Overall, this study identifies FIASMAs as host cell-directed therapeutics for treating infections caused by A. phagocytophilum, C. burnetii, C. pneumoniae, and potentially other pathogens whose infectivity, intracellular growth, and/or survival are strongly influenced by NPC1-trafficked LDL cholesterol. FIASMAs have a high likelihood for preventing resistance development, could be administered as an alternative to antibiotics when necessary or in conjunction with antimicrobial drugs to augment their efficacy, and therefore should be considered for evaluation in clinical settings.

\section{Materials and Methods}

\section{Cultivation of uninfected and infected cell lines}

Uninfected and A. phagocytophilum NCH-1 strain-infected human promyelocytic HL-60 cells (CCL-240; American Type Culture Collections [ATCC]) and RF/6A rhesus monkey choroidal endothelial cells (CRL-1780; ATCC) were cultured as previously described (Huang et al, 2010a). HeLa human cervical epithelial cells (CCL-2; ATCC) were maintained as described (Justis et al, 2017). C. burnetii Nine Mile Phase II (NMII; clone 4, RSA439) and mCherry-C. burnetii NMII were purified from Vero cells (African green monkey kidney epithelial cells; CCL-81; ATCC) or acidified citrate cysteine medium-2 (ACCM-2) and stored as described (Cockrell et al, 2008; Beare et al, 2009). Mouse alveolar macrophages (MH-S; CRL-2019; ATCC) and THP-1 human monocytic cells (TIB-202; ATCC) were maintained as described (Mulye et al, 2018). THP-1 cells were differentiated into macrophage-like cells by overnight treatment with $200 \mathrm{nM}$ phorbol 12-myrisate 13-acetate (MilliporeSigma). C. trachomatis serovar L2 (LGV 434) was maintained in HeLa cells at $37^{\circ} \mathrm{C}$ as described (Rucks et al, 2017). C. pneumoniae AR39 was maintained in HeLa cells at $35^{\circ} \mathrm{C}$ as described (Ouellette et al, 2016). Mammalian cell cultures were low passage and confirmed to be mycoplasma free using the Universal Mycoplasma Detection kit (ATCC) or Mycoplasma PCR Detection kit (MilliporeSigma).

\section{Antibodies and reagents}

Commercial antibodies targeted vimentin (product number ab8069; Abcam), CERT (product number GW22128B; MilliporeSigma), NPC1 (product number ab224268; Abcam), Beclin-1 (product number 207612; Abcam), TGN46 (product number 50595; Abcam), CD63 (product number 556019; BD Biosciences), VAMP4 (product number V4514; MilliporeSigma), syntaxin 6 (product number 610636; BD Biosciences), and LBPA (product number MABT837; MilliporeSigma). Antisera specific for APH0032, APH1235, and P44 were described previously (Huang et al, 2010a; Troese et al, 2011). Antibodies against C. pneumoniae were gifts from Ted Hackstadt (National Institute of Allergy and Infectious Diseases [NIAID]; Rocky Mountain Laboratories) or Harlan Caldwell (NIAID; Laboratory of Clinical Immunology and Microbiology). Antibodies against $C$. trachomatis were either a gift from Ted Hackstadt or antiMOMP (product number C01363; Meridian Life Science). Alexa fluorochrome-conjugated secondary antibodies were obtained from Invitrogen or Jackson ImmunoResearch Laboratories. Filipin (Cayman Chemical) was used to label endogenous cholesterol. LysoTracker Red (Invitrogen), TopFluor (BODIPY) Cholesterol (Avanti Polar Lipids), and BODIPY-TR ceramide (Invitrogen) were used for live cell experiments. DNA stains used were 1,5-bis\{[2-(di-methylamino) ethyl]amino\}-4, 8dihydroxyanthracene-9,10-dione (DRAQ5; Thermo Fisher Scientific), DAPI (Thermo Fisher Scientific), and Hoechst 33342 (Thermo Fisher Scientific). Chemical inhibitors used included desipramine (MilliporeSigma), amitriptyline (MilliporeSigma), nortriptyline (Milliporesigma), and CA-074 Me (MilliporeSigma).

\section{Isolation of human neutrophils}

Human neutrophils were isolated from peripheral blood of healthy donors by centrifugation through an equal volume of Polymorph 
Prep (Axis-Shield) at $470 \mathrm{~g}$ for $30 \mathrm{~min}$. The resulting neutrophil band was removed via aspiration and mixed with equal volumes of $0.45 \%$ (vol/vol) $\mathrm{NaCl}$ in PBS and RPMI 1640 (Thermo Fisher Scientific)- 0.5 mM EDTA (MilliporeSigma). The cells were centrifuged at $210 \mathrm{~g}$ for 10 min and resuspended in Red Blood Cell Lysis Buffer (Thermo Fisher Scientific) for 5 min, washed twice with RPMI 1640-0.5 mM EDTA, and resuspended in RPMI 1640. All investigations using neutrophils obtained from human donor blood were conducted according to the principles expressed in the Helsinki Declaration, and informed consent was obtained from all subjects. The protocol (HM11407) for obtaining donor blood for the purpose of isolating neutrophils has been reviewed and approved by the Virginia Commonwealth University Institutional Review Board with respect to scientific content and compliance with applicable research and human subject regulations.

\section{Infection assays}

For A. phagocytophilum infections, HL-60 cells, RF/6A cells, or human neutrophils were treated for $1 \mathrm{~h}$ with 1-10 $\mu \mathrm{M}$ desipramine, $10 \mu \mathrm{M}$ amitriptyline, $10 \mu \mathrm{M}$ nortriptyline, or DMSO before incubation with A. phagocytophilum DC organisms as described (Troese \& Carlyon, 2009; Truchan et al, 2016a, 2016c) in the continued presence of FIAMSA unless otherwise noted. In some instances, HL-60 cells were infected before desipramine treatment or A. phagocytophilum DC organisms were treated with desipramine before incubation with host cells, whereas in others desipramine was either added to or removed from A. phagocytophilum-infected HL60 cells at $20 \mathrm{~h}$. To confirm that desipramine's inhibitory effect on $A$. phagocytophilum was specific to its action on ASM and not acid ceramidase, HL-60 cells were pretreated with $5 \mu \mathrm{M}$ CA-074 Me before desipramine treatment and $A$. phagocytophilum infection.

For C. burnetii infections, MH-S or HeLa cells were treated for $1 \mathrm{~h}$ with desipramine or DMSO and infected as previously described with mCherry-expressing small cell variants for $1 \mathrm{~h}$ (Mulye et al, 2017; Clemente et al, 2018). Infection conditions were optimized for both cell type and vessel for less than one internalized bacterium per cell. THP-1 macrophage-like cells were infected with mCherryexpressing C. burnetii at a multiplicity of infection (MOI) of 10 in the presence of $10 \mu \mathrm{M}$ desipramine or DMSO.

For C. trachomatis infections, HeLa cells were treated for $1 \mathrm{~h}$ with $10 \mu \mathrm{M}$ desipramine or DMSO, then infected at an MOI of 0.5 by adding inoculum to tissue culture wells and centrifuging the tissue culture plates at $400 \mathrm{~g}$ for $15 \mathrm{~min}$ at room temperature, followed by incubation at $37^{\circ} \mathrm{C}, 5 \% \mathrm{CO}_{2}$, for the indicated time points. For $\mathrm{C}$. pneumoniae infections, HeLa cells were inoculated at an $\mathrm{MOI}$ of 2 as described for $C$. trachomatis infections with the exception that infected monolayers were incubated at $35^{\circ} \mathrm{C}, 5 \% \mathrm{CO}_{2}$. At $2-3 \mathrm{~h}$ postinfection, the medium was changed and $10 \mu \mathrm{M}$ desipramine or DMSO was added. To assess chlamydial-infectious progeny production, infected monolayers were scraped and centrifuged at $17,000 \mathrm{~g}$ for $30 \mathrm{~min}$ at $4^{\circ} \mathrm{C}$. The pellets were resuspended in sucrose phosphate buffer and vortexed in the presence of glass beads. Resulting lysates were serially diluted and plated onto fresh HeLa cells in the absence of desipramine. Monolayers were centrifuged at $400 \mathrm{~g}$ for $15 \mathrm{~min}$ at room temperature. C. trachomatis-infected cells were placed at $37^{\circ} \mathrm{C}, 5 \% \mathrm{CO}_{2}$, and incubated for an additional
24 h. C. pneumoniae-infected cells were placed at $35^{\circ} \mathrm{C}, 5 \% \mathrm{CO}_{2}$, and incubated for an additional 64 h. For A. phagocytophilum, C. burnetii, and chlamydial infection experiments in which desipramine treatment extended beyond $24 \mathrm{~h}$, fresh medium containing desipramine or DMSO was added to the cultures every $24 \mathrm{~h}$.

\section{Immunofluorescence microscopy}

For A. phagocytophilum immunofluorescence assays, infected RF/ 6 A cells on 12-mm glass coverslips (Electron Microscopy Sciences) were fixed in 4\% (vol/vol) PFA (Electron Microscopy Sciences) in PBS for $20 \mathrm{~min}$ followed by permeabilization with $0.5 \%$ (vol/vol) Triton $\mathrm{X}-100$ in PBS for $15 \mathrm{~min}$. Immunofluorescence labeling was performed as previously described (Huang et al, 2010a) followed by DAPI staining of DNA and mounting with Prolong Gold antifade reagent (Thermo Fisher Scientific). Images were obtained at room temperature using a Zeiss LSM 700 laser-scanning confocal microscope (Zeiss) and a 63× oil-immersion objective with a $1.4 \mathrm{nu}$ merical aperture. Images were acquired using Zeiss Efficient Navigation Imaging Suite 2.3 Blue Edition. For C. burnetii immunofluorescence assays, infected HeLa cells on 12-mm glass coverslips were fixed with 2.5\% (vol/vol) PFA in PBS for $15 \mathrm{~min}$, followed by permeabilization and blocking in PBS containing $0.1 \%$ (vol/vol) saponin and 1\% BSA. Immunofluorescence staining with CD63 antibody was performed as previously described (Justis et al, 2017) and mounted with Prolong Gold antifade reagent. Images were obtained at room temperature using a Nikon TiE inverted microscope with $60 \times$ oil immersion objective having a 1.4 numerical aperture and an ORCA-Flash $4.0 \mathrm{LT}+$ sCMOS camera (Hammamatsu). Chlamydial infected cells were imaged at room temperature using a Zeiss LSM 810 laser-scanning confocal microscope with a $63 \times$ oil immersion objective having a 1.4 numerical aperture. Images were acquired using Zeiss Efficient Navigation Imaging Suite 2.3 Blue Edition. Inclusion-forming units were calculated using an Olympus CKX53 microscope with a 40x objective. Inclusion-forming units per $\mathrm{mL}$ were determined by calculating the average number of inclusions per field of view multiplied by the dilution factor and the number of fields of view per well, divided by the volume of the original inoculum. The number of fields of view per well was determined by dividing the surface area of the tissue culture well by the view area of the field.

\section{Fluorescent analogue labeling}

For filipin labeling, infected cells were fixed in 2.5\% (vol/vol) PFA in PBS on ice for $15 \mathrm{~min}$ and incubated with filipin in 1\% (vol/vol) BSA in PBS for $1 \mathrm{~h}$ as previously described (Mulye et al, 2017). The cells were mounted with Prolong Gold antifade reagent lacking DAPI and imaged via confocal microscopy. For BODIPY cholesterol labeling, live A. phagocytophilum-infected RF/6A cells were incubated with 4 $\mathrm{mg} \mathrm{ml} \mathrm{ml}^{-1}$ BODIPY cholesterol in cholesterol-free medium for a minimum of $18 \mathrm{~h}$ to allow the cholesterol to accumulate in lysosomes and washed with Hepes (Thermo Fisher Scientific) twice. The cells were then incubated with BODIPY ceramide in Hepes per the manufacturer's instructions and stained with Hoechst 33342 (Invitrogen) to label host cell nuclei and bacteria. In some instances, live cells were incubated with LysoTracker Red in media for 
$3 \mathrm{~h}$ to identify acidic compartments. The live cells were then imaged at room temperature with a Leica TCS SP8 microscope (Leica) affixed with an Andor iXon Life 888 EMCCD camera (Oxford Instruments) and a $63 \times$ water-immersion objective with a 1.2 numeric aperture. Images were acquired using Leica Application Suite $X$ software. The brightness of post-acquisition images of RF/6A cells labeled with LysoTracker Red, BODIPY cholesterol, and Hoechst 33342 was increased using PowerPoint version 16.16.3 (Microsoft)

\section{qPCR and $q R T-P C R$}

To analyze the A. phagocytophilum load after inhibitor treatment, DNA was isolated from the infected cells with the DNeasy Blood and Tissue kit (QIAGEN). Bacterial load in infected HL-60 and RF/6A cells was determined using primers specific for A. phagocytophilum $16 \mathrm{~S}$ rDNA and $\beta$-actin (Oki et al, 2016), the latter of which target conserved sequences among human, primate, and murine $\beta$-actin, SsoFast EvaGreen Supermix (Bio-Rad), and 100 ng template DNA. Thermal cycling conditions used were $98^{\circ} \mathrm{C}$ for $2 \mathrm{~min}$, followed by 40 cycles of $98^{\circ} \mathrm{C}$ for $5 \mathrm{~S}$ and $55^{\circ} \mathrm{C}$ for $10 \mathrm{~s}$. Relative $16 \mathrm{~S}$ rDNA was normalized to $\beta$-actin using the $2^{-\triangle \Delta C T}$ (Livak) method (Livak \& Schmittgen, 2001). Total RNA isolated from A. phagocytophiluminfected HL-60 cells using the RNeasy RNA Isolation kit (QIAGEN) was treated with DNase I (Invitrogen) and used as template for cDNA synthesis with the iScript Reverse Transcription Supermix (Bio-Rad). $1 \mu$ l of a 1:10 dilution of the cDNA was used as a template for qRT-PCR as described (Kahlon et al, 2013) using primers specific for $\beta$-actin, A. phagocytophilum 16S rDNA, and aph1235 (Troese et al, 2011). Thermal cycling conditions used were $98^{\circ} \mathrm{C}$ for $30 \mathrm{~s}$, followed by 40 cycles of $98^{\circ} \mathrm{C}$ for $5 \mathrm{~S}$ and $60^{\circ} \mathrm{C}$ for $5 \mathrm{~s}$. Relative aph 1235 transcript levels were normalized to $16 \mathrm{~S}$ rRNA levels using the $2^{-\triangle \Delta C T}$ method.

\section{C. burnetii CFU assay}

Viable C. burnetii were assayed using a CFU assay as previously described (Clemente et al, 2018). Briefly, bacteria were recovered from infected cells using water lysis as described (Mulye et al, 2017). The released bacteria were serially diluted in ACCM-2 and spotted in duplicate onto $0.25 \%$ ACCM-2 with tryptophan agarose plates (Vallejo Esquerra et al, 2017). The plates were incubated for 9-12 d at $37^{\circ} \mathrm{C}, 2.5 \% \mathrm{O}_{2}$, and $5 \% \mathrm{CO}_{2}$; Colony numbers were determined to measure viable bacteria. Each experiment was performed in biological duplicate.

\section{Mouse studies}

$\mathrm{ASM}^{-1-}$ mice were a gift from Pin-Lan Li (Virginia Commonwealth University, Richmond, VA). 6-8-wk-old $\mathrm{ASM}^{-1-}$ or C57Bl/ 6 male mice were injected intraperitoneally with $10^{8} \mathrm{~A}$. phagocytophilum DC organisms as described (Naimi et al, 2018). Male mice were exclusively used because they are more susceptible to A. phagocytophilum infection than female mice (Naimi et al, 2018). For desipramine treatment studies, 6-8-wk-old C57Bl/6 male mice were intraperitoneally injected twice per day with either $10 \mathrm{mg} \cdot \mathrm{kg}^{-1}$ desipramine or PBS on days 7-12 post A. phagocytophilum infection as described (Teichgraber et al, 2008). DNA was isolated from blood collected via the tail vein on days $4,8,12,16,21$, and 28 postinfection using the DNeasy Blood and Tissue kit (QIAGEN). The peripheral blood A. phagocytophilum load was determined by qPCR as described above except that $50 \mathrm{ng}$ of DNA was used as template. Thermal cycling conditions used were $98^{\circ} \mathrm{C}$ for $2 \mathrm{~min}$, followed by 40 cycles of $98^{\circ} \mathrm{C}$ for $5 \mathrm{~S}$ and $60^{\circ} \mathrm{C}$ for $30 \mathrm{~s}$. Mice were euthanized on day 28. All animal research was conducted in compliance with the Health and Human Services Guide for the Care and Use of Laboratory Animals and performed under the approval of the Institutional Animal Care and Use Committee at Virginia Commonwealth University (Protocol AM10220).

\section{Statistical analyses}

Statistical analyses were performed using the Prism 5.0 software package (GraphPad). One-way ANOVA with Tukey's post hoc test was used to test for a significant difference among groups. $t$ test was used to test for a significant difference among pairs. Statistical significance was set at $P$ values of $<0.05$. Vacuole size measurements were done with ImageJ (W. S. Rasband, National Institutes of Health) (Schindelin et al, 2012).

\section{Supplementary Information}

Supplementary Information is available at https://doi.org/10.26508/lsa. 201800292

\section{Acknowledgements}

We thank Joao F Pedra (University of Maryland, Baltimore, MD), Robert A Heinzen (NIAID, Hamilton, MT), and Ted Hackstadt (NIAID, Hamilton, MT) for critical review of this manuscript. We thank Waheeda A Naimi for technical assistance. Confocal micrographs of A. phagocytophilum-infected cells were obtained at the VCU Microscopy Facility, which is supported, in part, with funding from National Institutes of Health - National Institute of Neurological Disorders and Stroke (NIH-NINDS) Center core grant 5P30NS047463 and NIH-NCl Cancer Center Support Grant (P30 CA016059). Chlamydial images were acquired with the assistance of Janice $A$ Taylor and James $R$ Talaska in the University of Nebraska Medical Center Advanced Microscopy Core Facility, which is funded by the Fred and Pamela Buffet Cancer Center Support Grant (P30CA036727) and an Institutional Development Award from National Institute of General Medical Sciences (NIGMS) of the NIH (P30GM106397). JA Carlyon is supported by National Institutes of Health National Institute of Allergy and Infectious Diseases (NIH-NIAID) grants 1R01 Al139072 and 2R01 AI072683. CE Chalfant is supported by NIH-NIAID grant 1R01 Al139072. DH Conrad is supported by NIH-NIAID grant 5R01 AI018697. DE Voth is supported by NIH-NIAID grant 1R21 Al127931 and NIH/NIGMS grant 1P20 GM103625. EA Rucks is supported by 1R01 Al114670 and University of Nebraska Medical Center (UNMC) start-up funds. SD Gilk is supported by NIH-NIAID grants R21Al121786 and R01Al139176.

\section{Author Contributions}

CL Cockburn: conceptualization, data curation, formal analysis, supervision, investigation, methodology, and writing-original draft, review, and editing

RS Green: data curation, formal analysis, investigation, and writingreview and editing. 
SR Damle: data curation, investigation, and writing-review and editing.

RK Martin: data curation, investigation, and writing-review and editing

NN Ghahrai: data curation, investigation, and writing-review and editing.

PM Colonne: data curation, investigation, and writing-review and editing.

MS Fullerton: data curation, investigation, and writing-review and editing.

DH Conrad: formal analysis, supervision, funding acquisition, validation, and writing-review and editing.

CE Chalfant: conceptualization, formal analysis, funding acquisition, and writing-review and editing.

DE Voth: conceptualization, resources, formal analysis, supervision, funding acquisition, methodology, and writing-original draft, review, and editing

EA Rucks: conceptualization, resources, data curation, formal analysis, funding acquisition, investigation, methodology, and writing-original draft, review, and editing.

SD Gilk: conceptualization, resources, data curation, formal analysis, funding acquisition, investigation, methodology, and writingoriginal draft, review, and editing.

J Carlyon: conceptualization, resources, data curation, formal analysis, supervision, funding acquisition, validation, methodology, project administration, and writing-original draft, review, and editing.

\section{Conflict of Interest Statement}

The authors declare that they have no conflict of interest.

\section{References}

Abdelrahman YM, Belland RJ (2005) The chlamydial developmental cycle. FEMS Microbiol Rev 29: 949-959. doi:doi:10.1016/j.femsre.2005.03.002

Abdul-Hammed M, Breiden B, Adebayo MA, Babalola JO, Schwarzmann G, Sandhoff K (2010) Role of endosomal membrane lipids and NPC2 in cholesterol transfer and membrane fusion. J Lipid Res 51: 1747-1760. doi:doi:10.1194/jlr.m003822

Alberdi P, Espinosa PJ, Cabezas-Cruz A, de la Fuente J (2016) Anaplasma phagocytophilum manipulates host cell apoptosis by different mechanisms to establish infection. Vet Sci 3: E15. doi:doi:10.3390/ vetsci3030015

Beare PA, Howe D, Cockrell DC, Omsland A, Hansen B, Heinzen RA (2009) Characterization of a Coxiella burnetii ftsZ mutant generated by Himar1 transposon mutagenesis. J Bacteriol 191: 1369-1381. doi: doi:10.1128/jb.01580-08

Beatty WL (2006) Trafficking from CD63-positive late endocytic multivesicular bodies is essential for intracellular development of Chlamydia trachomatis. J Cell Sci 119: 350-359. doi:doi:10.1242/jcs.02733

Beatty WL (2008) Late endocytic multivesicular bodies intersect the chlamydial inclusion in the absence of CD63. Infect Immun 76: 2872-2881. doi:doi:10.1128/iai.00129-08

Brady RO, Kanfer JN, Mock MB, Fredrickson DS (1966) The metabolism of sphingomyelin. II. Evidence of an enzymatic deficiency in NiemannPick diseae. Proc Natl Acad Sci U S A 55: 366-369. doi:doi:10.1073/ pnas.55.2.366
Burillo A, Bouza E (2010) Chlamydophila pneumoniae. Infect Dis Clin North Am 24: 61-71. doi:doi:10.1016/j.idc.2009.10.002

Carabeo RA, Mead DJ, Hackstadt T (2003) Golgi-dependent transport of cholesterol to the Chlamydia trachomatis inclusion. Proc Natl Acad Sci U S A 100: 6771-6776. doi:doi:10.1073/pnas.1131289100

Clemente TM, Mulye M, Justis AV, Nallandhighal S, Tran TM, Gilk SD (2018) Coxiella burnetii blocks intracellular interleukin-17 signaling in macrophages. Infect Immun 86. doi:doi:10.1128/iai.00532-18

Cocchiaro JL, Kumar Y, Fischer ER, Hackstadt T, Valdivia RH (2008) Cytoplasmic lipid droplets are translocated into the lumen of the Chlamydia trachomatis parasitophorous vacuole. Proc Natl Acad Sci U S A 105: 9379-9384. doi:doi:10.1073/pnas.0712241105

Cockrell DC, Beare PA, Fischer ER, Howe D, Heinzen RA (2008) A method for purifying obligate intracellular Coxiella burnetii that employs digitonin lysis of host cells. J Microbiol Methods 72: 321-325. doi: doi:10.1016/j.mimet.2007.12.015

Coppens I, Sinai AP, Joiner KA (2000) Toxoplasma gondii exploits host lowdensity lipoprotein receptor-mediated endocytosis for cholesterol acquisition. J Cell Biol 149: 167-180. doi:doi:10.1083/jcb.149.1.167

Cox JV, Naher N, Abdelrahman YM, Belland RJ (2012) Host HDL biogenesis machinery is recruited to the inclusion of Chlamydia trachomatisinfected cells and regulates chlamydial growth. Cell Microbiol 14: 1497-1512. doi:doi:10.1111/j.1462-5822.2012.01823.x

Czyz DM, Potluri LP, Jain-Gupta N, Riley SP, Martinez JJ, Steck TL, Crosson S, Shuman HA, Gabay JE (2014) Host-directed antimicrobial drugs with broad-spectrum efficacy against intracellular bacterial pathogens. MBio 5: e01534-e01514. doi:doi:10.1128/mbio.00931-14

Derre I, Swiss R, Agaisse H (2011) The lipid transfer protein CERT interacts with the Chlamydia inclusion protein InCD and participates to ERChlamydia inclusion membrane contact sites. PLOS Pathog 7 : e1002092. doi:doi:10.1371/journal.ppat.1002092

Dunning Hotopp JC, Lin M, Madupu R, Crabtree J, Angiuoli SV, Eisen JA, Seshadri R, Ren Q, Wu M, Utterback TR, et al (2006) Comparative genomics of emerging human ehrlichiosis agents. PLoS Genet 2: e21. doi:doi:10.1371/journal.pgen.0020021

Elojeimy S, Holman DH, Liu X, El-Zawahry A, Villani M, Cheng JC, Mahdy A Zeidan Y, Bielwaska A, Hannun YA, et al (2006) New insights on the use of desipramine as an inhibitor for acid ceramidase. FEBS Lett 580: 4751-4756. doi:doi:10.1016/j.febslet.2006.07.071

Elwell CA, Jiang S, Kim JH, Lee A, Wittmann T, Hanada K, Melancon P, Engel JN (2011) Chlamydia trachomatis co-opts GBF1 and CERT to acquire host sphingomyelin for distinct roles during intracellular development. PLOS Pathog 7: e1002198. doi:doi:10.1371/journal.ppat.1002198

Flores-Diaz M, Monturiol-Gross L, Naylor C, Alape-Giron A, Flieger A (2016) Bacterial sphingomyelinases and phospholipases as virulence factors. Microbiol Mol Biol Rev 80: 597-628. doi:doi:10.1128/ mmbr.00082-15

Hayasaka Y, Purgato M, Magni LR, Ogawa Y, Takeshima N, Cipriani A, Barbui C, Leucht S, Furukawa TA (2015) Dose equivalents of antidepressants: Evidence-based recommendations from randomized controlled trials. J Affect Disord 180: 179-184. doi:doi:10.1016/j.jad.2015.03.021

Howe D, Heinzen RA (2006) Coxiella burnetii inhabits a cholesterol-rich vacuole and influences cellular cholesterol metabolism. Cell Microbiol 8: 496-507. doi:doi:10.1111/j.1462-5822.2005.00641.x

Huang B, Troese MJ, Howe D, Ye S, Sims JT, Heinzen RA, Borjesson DL, Carlyon JA (2010a) Anaplasma phagocytophilum APH_0032 is expressed late during infection and localizes to the pathogen-occupied vacuolar membrane. Microb Pathog 49: 273-284. doi:doi:10.1016/j. micpath.2010.06.009

Huang B, Troese MJ, Ye S, Sims JT, Galloway NL, Borjesson DL, Carlyon JA (2010b) Anaplasma phagocytophilum APH_1387 is expressed throughout bacterial intracellular development and localizes to the 
pathogen-occupied vacuolar membrane. Infect Immun 78: 1864-1873. doi:doi:10.1128/iai.01418-09

Ismail N, McBride JW (2017) Tick-borne emerging infections: Ehrlichiosis and anaplasmosis. Clin Lab Med 37: 317-340. doi:doi:10.1016/j. cll.2017.01.006

Jones RB, Van der Pol B, Martin DH, Shepard MK (1990) Partial characterization of Chlamydia trachomatis isolates resistant to multiple antibiotics. J Infect Dis 162: 1309-1315. doi:doi:10.1093/infdis/ 162.6.1309

Justis AV, Hansen B, Beare PA, King KB, Heinzen RA, Gilk SD (2017) Interactions between the Coxiella burnetii parasitophorous vacuole and the endoplasmic reticulum involve the host protein ORP1L. Cell Microbiol 19. doi:doi:10.1111/cmi.12637

Kabeiseman EJ, Cichos K, Hackstadt T, Lucas A, Moore ER (2013) Vesicleassociated membrane protein 4 and syntaxin 6 interactions at the chlamydial inclusion. Infect Immun 81: 3326-3337. doi:doi:10.1128/ iai.00584-13

Kahlon A, Ojogun N, Ragland SA, Seidman D, Troese MJ, Ottens AK, Mastronunzio JE, Truchan HK, Walker NJ, Borjesson DL, et al (2013) Anaplasma phagocytophilum Asp14 is an invasin that interacts with mammalian host cells via its $C$ terminus to facilitate infection. Infect Immun 81: 65-79. doi:doi:10.1128/iai.00932-12

Klein MB, Miller JS, Nelson CM, Goodman JL (1997) Primary bone marrow progenitors of both granulocytic and monocytic lineages are susceptible to infection with the agent of human granulocytic ehrlichiosis. J Infect Dis 176: 1405-1409. doi:doi:10.1086/517332

Kohler LJ, Roy CR (2015) Biogenesis of the lysosome-derived vacuole containing Coxiella burnetii. Microbes Infect 17: 766-771. doi: doi:10.1016/j.micinf.2015.08.006

Kornhuber J, Rhein C, Muller CP, Muhle C (2015) Secretory sphingomyelinase in health and disease. Biol Chem 396: 707-736. doi:doi:10.1515/hsz2015-0109

Kornhuber J, Tripal P, Reichel M, Muhle C, Rhein C, Muehlbacher M, Groemer TW, Gulbins E (2010) Functional Inhibitors of Acid Sphingomyelinase (FIASMAs): A novel pharmacological group of drugs with broad clinical applications. Cell Physiol Biochem 26: 9-20. doi:doi:10.1159/000315101

Kumar Y, Cocchiaro J, Valdivia RH (2006) The obligate intracellular pathogen Chlamydia trachomatis targets host lipid droplets. Curr Biol 16: 1646-1651. doi:doi:10.1016/j.cub.2006.06.060

Kuzu OF, Gowda R, Noory MA, Robertson GP (2017) Modulating cancer cell survival by targeting intracellular cholesterol transport. $\mathrm{Br} /$ Cancer 117: 513-524. doi:doi:10.1038/bjc.2017.200

Lefevre JC, Lepargneur JP, Guion D, Bei S (1997) Tetracycline-resistant Chlamydia trachomatis in Toulouse, France. Pathol Biol (Paris) 45: 376-378.

Lin M, Rikihisa Y (2003) Ehrlichia chaffeensis and Anaplasma phagocytophilum lack genes for lipid A biosynthesis and incorporate cholesterol for their survival. Infect Immun 71: 5324-5331. doi: doi:10.1128/iai.71.9.5324-5331.2003

Liu W, He P, Cheng B, Mei CL, Wang YF, Wan JJ (2010) Chlamydia pneumoniae disturbs cholesterol homeostasis in human THP-1 macrophages via JNK-PPARgamma dependent signal transduction pathways. Microbes Infect 12: 1226-1235. doi:doi:10.1016/j.micinf.2010.09.004

Livak KJ, Schmittgen TD (2001) Analysis of relative gene expression data using real-time quantitative PCR and the 2(-Delta Delta C(T)) Method. Methods 25: 402-408. doi:doi:10.1006/meth.2001.1262

Lloyd-Evans E, Morgan AJ, He X, Smith DA, Elliot-Smith E, Sillence DJ, Churchill GC, Schuchman EH, Galione A, Platt FM (2008) Niemann-Pick disease type C1 is a sphingosine storage disease that causes deregulation of lysosomal calcium. Nat Med 14: 1247-1255. doi:doi:10.1038/nm.1876

Mastronunzio JE, Kurscheid S, Fikrig E (2012) Postgenomic analyses reveal development of infectious Anaplasma phagocytophilum during transmission from ticks to mice. J Bacteriol 194: 2238-2247. doi: doi:10.1128/jb.06791-11

Moore ER, Mead DJ, Dooley CA, Sager J, Hackstadt T (2011) The trans-Golgi SNARE syntaxin 6 is recruited to the chlamydial inclusion membrane. Microbiology 157: 830-838. doi:doi:10.1099/mic.0.045856-0

Mott J, Barnewall RE, Rikihisa Y (1999) Human granulocytic ehrlichiosis agent and Ehrlichia chaffeensis reside in different cytoplasmic compartments in HL-60 cells. Infect Immun 67: 1368-1378.

Mulye M, Samanta D, Winfree S, Heinzen RA, Gilk SD (2017) Elevated cholesterol in the Coxiella burnetii intracellular niche is bacteriolytic. MBio 8. doi:doi:10.1128/mbio.02313-16

Mulye M, Zapata B, Gilk SD (2018) Altering lipid droplet homeostasis affects Coxiella burnetii intracellular growth. PLoS One 13: e0192215. doi: doi:10.1371/journal.pone.0192215

Munderloh UG, Lynch MJ, Herron MJ, Palmer AT, Kurtti TJ, Nelson RD, Goodman $J L$ (2004) Infection of endothelial cells with Anaplasma marginale and A. phagocytophilum. Vet Microbiol 101: 53-64. doi:doi:10.1016/j. vetmic.2004.02.011

Naimi WA, Green RS, Cockburn CL, Carlyon JA (2018) Differential susceptibility of male versus female laboratory mice to anaplasma phagocytophilum infection. Trop Med Infect Dis 3: E78. doi:doi:10.3390/ tropicalmed3030078

Niu H, Xiong Q, Yamamoto A, Hayashi-Nishino M, Rikihisa Y (2012) Autophagosomes induced by a bacterial Beclin 1 binding protein facilitate obligatory intracellular infection. Proc Natl Acad Sci U S A 109: 20800-20807. doi:doi:10.1073/pnas.1218674109

Oki AT, Huang B, Beyer AR, May LJ, Truchan HK, Walker NJ, Galloway NL, Borjesson DL, Carlyon JA (2016) Anaplasma phagocytophilum APH0032 is exposed on the cytosolic face of the pathogen-occupied vacuole and co-opts host cell SUMOylation. Front Cell Infect Microbiol 6: 108 doi:doi:10.3389/fcimb.2016.00108

Oninla VO, Breiden B, Babalola JO, Sandhoff K (2014) Acid sphingomyelinase activity is regulated by membrane lipids and facilitates cholesterol transfer by NPC2. J Lipid Res 55: 2606-2619. doi:doi:10.1194/jlr.m054528

Ouellette SP, Messerli PR, Wood NA, Hajovsky H (2018) Characterization of chlamydial rho and the role of rho-mediated transcriptional polarity during interferon gamma-mediated tryptophan limitation. Infect Immun 86. doi:doi:10.1128/iai.00240-18

Ouellette SP, Rueden KJ, Rucks EA (2016) Tryptophan codon-dependent transcription in Chlamydia pneumoniae during gamma interferonmediated tryptophan limitation. Infect Immun 84: 2703-2713. doi: doi:10.1128/iai.00377-16

Peng H, Li C, Kadow S, Henry BD, Steinmann J, Becker KA, Riehle A, Beckmann N, Wilker B, Li PL, et al (2015) Acid sphingomyelinase inhibition protects mice from lung edema and lethal Staphylococcus aureus sepsis. J Mol Med (Berl) 93: 675-689. doi:doi:10.1007/s00109-014-1246-y

Rouli L, Rolain JM, El Filali A, Robert C, Raoult D (2012) Genome sequence of Coxiella burnetii 109, a doxycycline-resistant clinical isolate. $J$ Bacteriol 194: 6939. doi:doi:10.1128/jb.01856-12

Rucks EA, Olson MG, Jorgenson LM, Srinivasan RR, Ouellette SP (2017) Development of a proximity labeling system to map the Chlamydia trachomatis inclusion membrane. Front Cell Infect Microbiol 7: 40. doi: doi:10.3389/fcimb.2017.00040

Samanta D, Mulye M, Clemente TM, Justis AV, Gilk SD (2017) Manipulation of host cholesterol by obligate intracellular bacteria. Front Cell Infect Microbiol 7: 165. doi:doi:10.3389/fcimb.2017.00165

Sandoz KM, Rockey DD (2010) Antibiotic resistance in chlamydiae. Future Microbiol 5: 1427-1442. doi:doi:10.2217/fmb.10.96

Schindelin J, Arganda-Carreras I, Frise E, Kaynig V, Longair M, Pietzsch T, Preibisch S, Rueden C, Saalfeld S, Schmid B, et al (2012) Fiji: An opensource platform for biological-image analysis. Nat Methods 9: 676-682. doi:doi:10.1038/nmeth.2019 
Schuchman EH (2010) Acid sphingomyelinase, cell membranes and human disease: Lessons from niemann-pick disease. FEBS Lett 584: 1895-1900. doi:doi:10.1016/j.febslet.2009.11.083

Schuchman EH, Miranda SR (1997) Niemann-pick disease: Mutation update, genotype/phenotype correlations, and prospects for genetic testing. Genet Test 1: 13-19. doi:doi:10.1089/gte.1997.1.13

Somani J, Bhullar VB, Workowski KA, Farshy CE, Black CM (2000) Multiple drugresistant Chlamydia trachomatis associated with clinical treatment failure. J Infect Dis 181: 1421-1427. doi:doi:10.1086/315372

Spyridaki I, Psaroulaki A, Kokkinakis E, Gikas A, Tselentis Y (2002) Mechanisms of resistance to fluoroquinolones in Coxiella burnetii. J Antimicrob Chemother 49: 379-382. doi:doi:10.1093/jac/49.2.379

Sukumaran B, Mastronunzio JE, Narasimhan S, Fankhauser S, Uchil PD, Levy R, Graham M, Colpitts TM, Lesser CF, Fikrig E (2011) Anaplasma phagocytophilum AptA modulates Erk1/2 signalling. Cell Microbiol 13: 47-61. doi:doi:10.1111/j.1462-5822.2010.01516.x

Teichgraber V, Ulrich M, Endlich N, Riethmuller J, Wilker B, DeOliveiraMunding CC, van Heeckeren AM, Barr ML, von Kurthy G, Schmid KW, et al (2008) Ceramide accumulation mediates inflammation, cell death and infection susceptibility in cystic fibrosis. Nat Med 14: 382-391. doi:doi:10.1038/nm1748

Troese MJ, Carlyon JA (2009) Anaplasma phagocytophilum dense-cored organisms mediate cellular adherence through recognition of human P-selectin glycoprotein ligand 1. Infect Immun 77: 4018-4027. doi: doi:10.1128/iai.00527-09

Troese MJ, Kahlon A, Ragland SA, Ottens AK, Ojogun N, Nelson KT, Walker NJ, Borjesson DL, Carlyon JA (2011) Proteomic analysis of Anaplasma phagocytophilum during infection of human myeloid cells identifies a protein that is pronouncedly upregulated on the infectious dense-cored cell. Infect Immun 79: 4696-4707. doi: doi:10.1128/iai.05658-11

Truchan HK, Cockburn CL, Hebert KS, Magunda F, Noh SM, Carlyon JA (2016a) The pathogen-occupied vacuoles of anaplasma phagocytophilum and anaplasma marginale interact with the endoplasmic reticulum. Front Cell Infect Microbiol 6: 22. doi:doi:10.3389/fcimb.2016.00022

Truchan HK, Cockburn CL, May LJ, VieBrock L, Carlyon JA (2016b) Anaplasma phagocytophilum-occupied vacuole interactions with the host cell cytoskeleton. Vet Sci 3: E25. doi:doi:10.3390/vetsci3030025

Truchan HK, Seidman D, Carlyon JA (2013) Breaking in and grabbing a meal: Anaplasma phagocytophilum cellular invasion, nutrient acquisition, and promising tools for their study. Microbes Infect 15: 1017-1025. doi: doi:10.1016/j.micinf.2013.10.010

Truchan HK, VieBrock L, Cockburn CL, Ojogun N, Griffin BP, Wijesinghe DS, Chalfant CE, Carlyon JA (2016C) Anaplasma phagocytophilum Rab10dependent parasitism of the trans-Golgi network is critical for completion of the infection cycle. Cell Microbiol 18: 260-281. doi: doi:10.1111/cmi.12500
Urano Y, Watanabe H, Murphy SR, Shibuya Y, Geng Y, Peden AA, Chang CC, Chang TY (2008) Transport of LDL-derived cholesterol from the NPC1 compartment to the ER involves the trans-Golgi network and the SNARE protein complex. Proc Natl Acad Sci U S A 105: 16513-16518. doi: doi:10.1073/pnas.0807450105

Utermohlen O, Herz J, Schramm M, Kronke M (2008) Fusogenicity of membranes: The impact of acid sphingomyelinase on innate immune responses. Immunobiology 213: 307-314. doi:doi:10.1016/j. imbio.2007.10.016

Vallejo Esquerra E, Yang H, Sanchez SE, Omsland A (2017) Physicochemical and nutritional requirements for axenic replication suggest physiological basis for Coxiella burnetii niche restriction. Front Cell Infect Microbiol 7: 190. doi:doi:10.3389/fcimb.2017.00190

Vanier MT (2013) Niemann-Pick diseases. Handb Clin Neurol 113: 1717-1721. doi:doi:10.1016/b978-0-444-59565-2.00041-1

Vazquez CL, Rodgers A, Herbst S, Coade S, Gronow A, Guzman CA, Wilson MS, Kanzaki M, Nykjaer A, Gutierrez MG (2016) The proneurotrophin receptor sortilin is required for Mycobacterium tuberculosis control by macrophages. Sci Rep 6: 29332. doi:doi:10.1038/srep29332

Walpole GFW, Grinstein S, Westman J (2018) The role of lipids in host-pathogen interactions. IUBMB Life 70: 384-392. doi:doi:10.1002/iub.1737

Watarai M, Makino S, Michikawa M, Yanagisawa K, Murakami S, Shirahata T (2002) Macrophage plasma membrane cholesterol contributes to Brucella abortus infection of mice. Infect Immun 70: 4818-4825. doi: doi:10.1128/iai.70.9.4818-4825.2002

Webster P, IJdo JW, Chicoine LM, Fikrig E (1998) The agent of Human Granulocytic Ehrlichiosis resides in an endosomal compartment. J Clin Invest 101: 1932-1941. doi:doi:10.1172/jci1544

Wolf K, Fischer E, Hackstadt T (2000) Ultrastructural analysis of developmental events in Chlamydia pneumoniae-infected cells. Infect Immun 68: 2379-2385. doi:doi:10.1128/iai.68.4.2379-2385.2000

Wu Y, Gulbins E, Grassme H (2018) The function of sphingomyelinases in mycobacterial infections. Biol Chem 399: 1125-1133. doi:doi:10.1515/ hsz-2018-0179

Xiong Q, Lin M, Rikihisa Y (2009) Cholesterol-dependent anaplasma phagocytophilum exploits the low-density lipoprotein uptake pathway. PLoS Pathog 5: e1000329. doi:doi:10.1371/journal.ppat.1000329

Xiong Q, Rikihisa Y (2012) Subversion of NPC1 pathway of cholesterol transport by Anaplasma phagocytophilum. Cell Microbiol 14: 560-576. doi:doi:10.1111/j.1462-5822.2011.01742.x

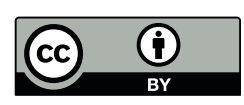

License: This article is available under a Creative Commons License (Attribution 4.0 International, as described at https://creativecommons.org/ licenses/by/4.0/). 